NBER WORKING PAPER SERIES

\title{
DEBT CONSTRAINTS AND EMPLOYMENT
}

\author{
Patrick Kehoe \\ Elena Pastorino \\ Virgiliu Midrigan
}

Working Paper 22614

http://www.nber.org/papers/w22614

\author{
NATIONAL BUREAU OF ECONOMIC RESEARCH \\ 1050 Massachusetts Avenue \\ Cambridge, MA 02138 \\ September 2016
}

We thank Eugenia Gonzalez Aguado, Julio Andres Blanco, Sonia Gilbukh, and Sergio Salgado Ibanez for excellent research assistance, and Joan Gieseke for invaluable editorial assistance. Kehoe thanks the National Science Foundation for financial support. The views expressed herein are those of the authors and not necessarily those of the Federal Reserve Bank of Minneapolis, the Federal Reserve System, or the National Bureau of Economic Research.

NBER working papers are circulated for discussion and comment purposes. They have not been peerreviewed or been subject to the review by the NBER Board of Directors that accompanies official NBER publications.

(C) 2016 by Patrick Kehoe, Elena Pastorino, and Virgiliu Midrigan. All rights reserved. Short sections of text, not to exceed two paragraphs, may be quoted without explicit permission provided that full credit, including $\odot$ notice, is given to the source. 
Debt Constraints and Employment

Patrick Kehoe, Elena Pastorino, and Virgiliu Midrigan

NBER Working Paper No. 22614

September 2016

JEL No. E21,E24,E32,J21,J64

\begin{abstract}
During the Great Recession, regions of the United States that experienced the largest declines in household debt also experienced the largest drops in consumption, employment, and wages. Employment declines were larger in the nontradable sector and for firms that were facing the worst credit conditions. Motivated by these findings, we develop a search and matching model with credit frictions that affect both consumers and firms. In the model, tighter debt constraints raise the cost of investing in new job vacancies and thus reduce worker job finding rates and employment. Two key features of our model, on-the-job human capital accumulation and consumer-side credit frictions, are critical to generating sizable drops in employment. On-the-job human capital accumulation makes the flows of benefits from posting vacancies long-lived and so greatly amplifies the sensitivity of such investments to credit frictions. Consumer-side credit frictions further magnify these effects by leading wages to fall only modestly. We show that the model reproduces well the salient cross-regional features of the U.S. data during the Great Recession.
\end{abstract}

\author{
Patrick Kehoe \\ Department of Economics \\ Stanford University \\ 579 Serra Mall \\ Virgiliu Midrigan \\ Department of Economics \\ New York University \\ Stanford, CA 94305 \\ 19 W. 4th St. \\ New York, NY 10012 \\ and NBER \\ and NBER \\ patrickjameskehoe@gmail.com \\ virgiliu.midrigan@nyu.edu \\ Elena Pastorino \\ Department of Economics \\ University of Minnesota \\ 4-101 Hanson Hall \\ 1925 Fourth Street South \\ Minneapolis, MN 55455 \\ and the Federal Reserve Bank of Minneapolis \\ epastori@umn.edu
}

A data appendix is available at http://www.nber.org/data-appendix/w22614 
A popular view of the 2007-2009 Great Recession in the United States is that large disruptions in the credit market played a critical role in generating the observed drop in output and employment. This view is motivated in part by the regional patterns documented in recent work by several authors. Mian and Sufi $(2011,2014)$ showed that regions of the Unites States with the largest declines in household debt and housing prices also experienced the largest declines in consumption and employment, especially nontradable employment. Beraja, Hurst, and Ospina (2016) showed that wages were moderately flexible in that they fell across regions almost as much as employment did. Finally, Giroud and Mueller (forthcoming) showed that employment fell the most in firms that were facing the worst credit conditions.

Motivated by these facts, we investigate the interplay between credit and labor market frictions, and how this interplay may have accounted for the Great Recession, by developing a version of the Diamond-Mortensen-Pissarides (DMP, henceforth) model with risk-averse agents, borrowing constraints, and human capital accumulation.

In the DMP model, hiring workers is an investment activity in that costs are paid up front, whereas benefits accrue gradually. As with any investment activity, the amount of such investments falls after a credit tightening, leading to a drop in employment. Although this force is present in any dynamic search model, the drop in employment following a tightening of credit is minuscule in the textbook version of the DMP model without human capital accumulation. This result is driven by the feature of the textbook DMP model that the flows of benefits from forming a match are very short-lived, with a (Macaulay) duration of two to three months, and is reminiscent of standard results in corporate finance that a tightening of credit has little impact on short-lived investments. (See, for example, Eisfeldt and Rampini (2007) and the references therein.)

The flows of benefits from forming a match are, in contrast, much longer-lived in the presence of on-the-job human capital accumulation, once this accumulation is calibrated so as to reproduce the evidence on how wages grow on the job and over the life cycle. With such human capital accumulation, a match not only produces current output but also raises a worker's human capital, an increase that persists far off into the future. In our model with human capital accumulation, the flows of benefits from a match are, therefore, longerlived with a duration on the order of 10 years and, hence, are much more sensitive to a credit tightening. We show that in the resulting model, the drop in employment following a tightening of credit is greatly amplified, and so the model accounts well for the regional patterns documented for the Great Recession.

To illustrate the workings of our mechanism, we first consider a one-good model. We then extend it to include tradable and nontradable goods in order to study its ability to account for the regional patterns just discussed. Specifically, we use the one-good model to 
show that allowing for human capital accumulation is critical for a tightening of credit to lead to a large reduction in employment. To build some intuition, consider a firm's incentives to post vacancies after a credit tightening. In response to such a tightening, consumption initially falls and then recovers, so that the marginal valuation of goods is especially high right after the shock but less so as time passes. That is, after a tightening, the shadow price of goods increases and then mean reverts. This increase in the shadow price of goods has two countervailing effects. First, it increases the effective cost of posting vacancies by raising the shadow value of the goods used in this investment. Second, it increases the benefits of doing so by raising the shadow value of the increased flow in output produced by consumers who switch from nonemployment to employment. Since the cost of posting vacancies is incurred immediately when goods are especially valuable, whereas the benefits accrue gradually in the future, the present value of the cost of posting vacancies rises by more than the present value of the benefits after a credit tightening. As a result, firms post fewer vacancies and thus employment falls.

This drop in vacancies is larger the longer the horizon over which the flow of benefits accrues. In the textbook DMP model without human capital accumulation, these benefits accrue quickly, because separation and job-finding rates are very high and, hence, an employed consumer produces more output than a nonemployed consumer for only a short period of time - a few months on average. Hence, a temporary increase in the shadow price of goods from a credit tightening increases the present value of benefits about as much as the costs, which has only a small negative effect on vacancy creation.

In our model with on-the-job human capital accumulation, in contrast, the benefits of posting vacancies accrue gradually over time. The reason is that human capital is partially transferable across matches so that its accumulation in a given match increases the output a consumer can produce in all future matches. Thus, in this model, a temporary increase in the shadow price of goods increases the present value of benefits of posting vacancies much less than their costs, and so it has a large negative effect on vacancy creation.

In sum, the textbook model is essentially static, so credit frictions have little effect. Adding human capital makes matches dynamic, so credit frictions can have large effects. Indeed, for the same tightening of credit, the model with human capital accumulation predicts a drop in employment that is 10 times larger than in the textbook model.

This discussion makes it clear that the amount of human capital acquired on the job and the extent to which human capital is transferable across matches are important determinants of the model's implications for how much employment drops following a tightening of credit. We allow human capital to be partially transferable across matches by assuming that consumers accumulate two types of human capital: general human capital that is fully 
transferable across matches and firm-specific human capital that fully depreciates when a match dissolves. We carefully parameterize each of these two components by requiring the model to be consistent with the existing evidence on how wages increase both on the job and over the life cycle.

In our baseline model, we quantify these parameters governing human capital accumulation by using moments derived from two sources of data: cross-sectional data from Elsby and Shapiro (2012) on how wages increase with experience and longitudinal data from Buchinsky et al. (2010) on how wages grow over an employment spell.

We show that our results are robust to using a range of estimates of wage growth in the literature, including estimates of how wages increase with experience from Rubinstein and Weiss (2006) and estimates of how wages grow over an employment spell from Altonji and Shakotko (1987) and Topel (1991). More generally, we find that in our model, the employment response to a credit tightening is determined almost entirely by the amount of overall lifecycle wage growth and is highly nonlinear. In particular, as long as life-cycle wage growth exceeds a threshold of about $1.5 \%$ per year, further increasing the amount of life-cycle wage growth has little effect on how employment responds to a credit tightening. In contrast, if life-cycle wage growth is below this threshold, further reducing the amount of life-cycle wage growth greatly diminishes the employment response to a credit tightening.

This nonlinearity stems from two of our model's implications. One, the duration of the flows of benefits from a match is a concave function of the rate of human capital accumulation. Two, a credit tightening leads to a transitory drop in consumption, so that flows received after some date in the future do not experience a large increase in their valuation, regardless of how distant they are. Because of this nonlinearity, our results are robust not only to estimates from the studies cited earlier, but also to any estimate of life-cycle wage growth above our $1.5 \%$ threshold - a threshold consistent with estimates in the literature. (See the survey by Rubinstein and Weiss (2006).)

We then use the model to examine the relative importance of consumer-side and firm-side credit frictions in accounting for movements in employment following a credit tightening. In our model, a tightening of credit to families effectively acts like a worsening of credit conditions faced by both consumers and firms. The reason is that we assume that consumers and firms belong to large families and that the credit tightening reduces a family's ability to borrow, thus raising both consumers' and firms' marginal valuation of goods.

If we assume, instead, that a credit tightening raises firms' valuations of goods, but not those of consumers, so that the latter are implicitly insulated from the credit crunch, we find that the responses of employment to the credit tightening are very modest. The reason is that following a tightening of credit that affects only firms' valuations, wages (counterfactu- 
ally) fall sharply. This drop in wages insulates firms from adverse credit conditions, giving them incentives to post almost as many vacancies as they did before the credit tightening. In contrast, when a credit tightening raises consumers' valuations as well, wages fall only modestly so that a firm's incentives to post vacancies are greatly reduced. Our model thus captures the idea that firms are unable to substantially lower the wages of their workers in the middle of a recession in which consumers are credit constrained.

We illustrate our results in a particularly simple model of credit frictions. We show, however, that for a large class of models, if shocks produce the same paths for consumption and, hence, the shadow prices of goods, then the models produce the same paths for labor market variables. To illustrate this point, we first show that our model has implications for employment and wages that are identical to those of an economy with housing in which debt is collateralized by the value of a house. This result allows us to rationalize the drop in employment as driven by a tightening of collateral constraints arising from a fall in the price of housing. We then show that our model has implications for employment and wages that are also identical to those of an economy with illiquid assets in which a tightening of debt constraints reduces the consumption of even wealthy households. This result allows us to think of our model as applying to (wealthy) net savers rather than only to net borrowers.

Taken together, these equivalence results show that the robust link across models is the link between consumption and labor market outcomes rather than the link between either house prices or levels of net assets and labor market outcomes. Motivated by these results, we focus our quantitative work on the link between consumption and labor market outcomes.

To confront the regional patterns discussed earlier that motivate our work, we extend our economy to include a large number of islands, each of which produces a nontradable good that is only consumed on the island and a tradable good that is consumed everywhere in the world. Each worker is endowed with one of two types of skills that are used with different intensities in the tradable and nontradable goods sectors. Labor is immobile across islands but can switch between sectors. This differential intensity of the use of skills across sectors generates a cost of reallocating workers between sectors.

In this economy, an island-specific debt tightening has two effects. The first, the investment effect, is similar to that in the one-good model: the cost of posting vacancies increases by more than the benefits, leading to a reduction in the number of vacancies and, hence, to a drop in overall employment on that island.

The second effect, the relative demand effect, is due to the reduction in the demand for the nontradable goods produced on the island. This drop in the demand for nontradable goods, in turn, leads to a drop in the demand for workers by that sector, which leads those workers to reallocate to the tradable goods sector. The smaller is the cost of reallocating workers, 
the larger is the reallocation and, thus, the larger is the drop in nontradable employment and the smaller is the drop in tradable employment.

We find that our model reproduces well the regional patterns during the Great Recession discussed earlier. In particular, a credit tightening that leads to a $10 \%$ fall in consumption across U.S. states between 2007 and 2009 is associated with a fall in nontradable employment of $5.5 \%$ and a negligible increase in tradable employment of $0.3 \%$. Our model has similar predictions: the same fall in consumption is associated with a fall in nontradable employment of $5.7 \%$ and a negligible increase in tradable employment of $0.3 \%$ across states. Our model also accounts for most of the resulting change in overall employment: such a drop in consumption is associated with a $3.8 \%$ drop in employment in the data and a $3.3 \%$ drop in the model across states.

Critically, our model is consistent with the Beraja, Hurst, and Ospina (2016) observation that in the cross section of U.S. states, wages are moderately flexible: a $10 \%$ drop in employment is associated with a fall in wages of $7.8 \%$ in both the data and the model. Thus, our model predicts sizable employment changes even though wages are as flexible as they are in the data.

Other Related Literature. In incorporating human capital accumulation into a search model, we build on the work of Ljungqvist and Sargent (1998, 2008). They extend McCall's (1970) model to include stochastic human capital accumulation on the job and depreciation off the job. Since they retain key features of the McCall model, such as linear preferences and an exogenous distribution of wages, the forces that drive our results are not present in their model. Instead, the forces that drive our results arise from embedding a related model of human capital accumulation into a general equilibrium DMP model with risk averse agents, endogenous wages, and endogenous vacancy creation.

Our work is complementary to that of Hall (2014), who studies the effects of changes in the discount rate in a search model. Hall's model features no human capital accumulation, and as such, implies short durations of the flows of benefits from matches. In contrast to our model, which assumes wages are determined through Nash bargaining, Hall (2014) assumes the bargaining protocol in Hall and Milgrom (2008), which implies that wages do not fall much in response to shocks. In our model, wages do not fall much in response to a credit tightening even with the standard Nash bargaining protocol. In this sense, our mechanism is complementary to that in Hall's work.

Our work is also closely related to that of Krusell et al. (2010) on the interaction between labor market frictions and asset market incompleteness. Their work focuses on an economy's response to aggregate productivity shocks but abstracts from human capital accumulation, 
whereas we focus on an economy's response to credit shocks in a model in which human capital accumulation plays a critical role.

Our work is related to a burgeoning literature that links a worsening of financial frictions on the consumer side to economic downturns. In particular, Guerrieri and Lorenzoni (2015), Eggertsson and Krugman (2012), and Midrigan and Philippon (2016) study macroeconomic responses to a household-side credit crunch. All three of these papers find that a credit crunch has only a minor, if any, negative impact on employment unless wages are sticky. Our analysis complements this work by studying a mechanism that does not impose sticky wages, but rather generates the downturn in employment within a search model in which wages are renegotiated every period through Nash bargaining.

Our model is also related to the work of Itskhoki and Helpman (2015) on sectoral reallocation in an open economy model with search frictions in the labor market, of Pinheiro and Visschers (2015) on endogenous compensating differentials and unemployment persistence in a labor market model with search frictions, as well as the work on house prices, credit, and business cycles of Ohanian (2010), Head and Lloyd-Ellis (2012), and the work comprehensively surveyed by Davis and Van Nieuwerburgh (2014).

Finally, our work is related to the large literature on financial intermediation, dating back at least to Bernanke and Gertler (1989), Kiyotaki and Moore (1997), and Bernanke, Gertler, and Gilchrist (1999). More recent work includes Mendoza (2010), Gertler and Karadi (2011), Gertler and Kiyotaki (2010), and Gilchrist and Zakrajšek (2012). This literature focuses on how credit frictions amplify the response of physical capital investment to shocks. Our work, instead, focuses on how credit shocks amplify employment responses in a model with labor market frictions and human capital. Moreover, this literature studies the overall effects of aggregate shocks, whereas we focus on the effects of regional shocks.

\section{A One-Good Economy}

We consider a small open economy, one-good DMP model. The economy consists of a continuum of firms and a continuum of consumers with stochastic lifetimes. Each consumer survives from one period to the next with probability $\phi$, and in each period a measure $1-\phi$ of new consumers is born, so that there is a constant measure 1 of consumers. Individual consumers accumulate general and firm-specific human capital and are subject to idiosyncratic shocks. Firms post vacancies in markets indexed by a consumer's human capital. Consumers are organized in families that insure idiosyncratic risks and own firms. Each family is subject to time-varying debt constraints. 


\subsection{Technologies}

Consumers are indexed by two state variables that summarize their ability to produce output. The variable $z_{t}$, referred to as general human capital, captures returns to experience and stays with the worker even after a job spell ends. The variable $h_{t}$, referred to as firm-specific human capital, captures returns to tenure and is reset every time a job spell ends. A consumer with state variables $\left(z_{t}, h_{t}\right)$ produces $z_{t} h_{t}$ when employed and $b\left(z_{t}\right)$ when not employed. General human capital thus affects a consumer's productivity both on the job and off the job.

Human capital evolves as follows. When the consumer is employed, general human capital evolves according to

$$
\log z_{t+1}=(1-\rho) \log \bar{z}_{e}+\rho \log z_{t}+\sigma_{z} \varepsilon_{t+1},
$$

where $\varepsilon_{t+1}$ is distributed normally with mean zero and variance 1 , whereas when the consumer is not employed, it evolves according to

$$
\log z_{t+1}=(1-\rho) \log \bar{z}_{u}+\rho \log z_{t}+\sigma_{z} \varepsilon_{t+1} .
$$

We assume that $\bar{z}_{u}<\bar{z}_{e}$. Newborn consumers start nonemployed with general human capital $z$, where $\log z$ is drawn from $N\left(\log \bar{z}_{u}, \sigma_{z}^{2} /\left(1-\rho_{z}^{2}\right)\right)$. This specification of human capital is in the spirit of that in Ljungqvist and Sargent (1998). We denote the Markov processes in (1) and (2) as $F_{e}\left(z_{t+1} \mid z_{t}\right)$ and $F_{u}\left(z_{t+1} \mid z_{t}\right)$ in what follows. The consumer's firm-specific human capital starts at $h_{t}=1$ whenever a job spell begins and then evolves on the job according to

$$
\log h_{t+1}=(1-\rho) \log \bar{h}+\rho \log h_{t},
$$

with $\bar{h}>1$. Both human capital components increase on average when a consumer is employed. The assumption that $\bar{z}_{u}<\bar{z}_{e}$ implies that when a consumer is employed, on average, the variable $z_{t}$ drifts up toward a high level of productivity $\bar{z}_{e}$ from the low average level of productivity $\bar{z}_{u}$ of newborn workers. Similarly, when the consumer is not employed, on average, the variable $z_{t}$ depreciates and hence drifts down toward a low level of productivity, $\bar{z}_{u}$, which we normalize to 1 . The assumption that $\bar{h}>1$ implies that when the consumer is employed, firm-specific human capital increases from $h=1$ toward $\bar{h}$ over time.

The parameter $\rho$ governs the rate at which general and firm-specific human capital converge toward their means. For simplicity, we assume that these rates are the same for all three laws of motion mentioned earlier. Allowing for idiosyncratic shocks $\varepsilon_{t+1}$ to general human capital allows the model to reproduce the dispersion in wage growth rates observed in the data. For simplicity only, we assume that the process for accumulating firm-specific capital is deterministic.

We represent the insurance arrangements in the economy by imagining that each consumer belongs to one of a large number of identical families, each of which has a continuum of 
household members who experience idiosyncratic shocks. The family as a whole receives a deterministic amount of income in each period from the income generated by its working and nonworking members. Risk sharing within the family implies that at date $t$, each household member consumes the same amount of consumption goods, $c_{t}$, regardless of the idiosyncratic shocks that such a member experiences. (This type of risk-sharing arrangement is familiar from the work of Merz (1995) and Andolfatto (1996).) The family as a whole is subject to time-varying debt constraints that limit the total amount of borrowing by the family. ${ }^{1}$

Given this setup, we can separate the problem of the family into two parts. The first part determines the common consumption level of every family member. The second part consists of the vacancy creation problem of each firm owned by the family.

\subsection{Consumption Choices}

We purposely consider a particularly simple model of a family's consumption-savings choice in order to focus attention on the interaction between credit and labor market frictions. In this model, the family trades a single risk-free security and faces exogenously-varying debt constraints. We later show that the model's implications for consumption, employment, and wages are equivalent to those of richer models in which debt is collateralized by housing, debt constraints tighten as house prices fall, and families are debt constrained even though they have savings in an illiquid asset.

Consider the consumption allocation problem of a family in the simple version of our model given by

$$
\max _{c_{t}, a_{t+1}} \sum_{t=0}^{\infty} \beta^{t} u\left(c_{t}\right)
$$

subject to a budget constraint

$$
c_{t}+q a_{t+1}=y_{t}+d_{t}+a_{t}
$$

and a debt constraint

$$
a_{t+1} \geqslant-\chi_{t}
$$

Here $\beta$ is the discount factor of the family, $c_{t}$ is consumption, $a_{t+1}$ are savings, $y_{t}$ represents the total income from the wages of the employed members of the family and home production of its nonemployed members, and $d_{t}$ are the profits from the firms the family owns. The family

\footnotetext{
${ }^{1}$ We also solved a version of the model similar to that in Krusell et al. (2010) in which consumers can only save with uncontingent bonds. This model has an unappealing feature. Because of human capital accumulation, the wage that solves the Nash bargaining problem is nonmonotonic in individual assets. In particular, there is a region of the parameter space in which higher assets reduce wages. Anticipating this effect, some consumers are deterred from saving because greater savings decrease their wages. This feature leads to odd patterns of wages and savings, and sometimes to the nonexistence of equilibrium.
} 
saves or borrows at a constant world bond price $q>\beta$ subject to an exogenous deterministic sequence $\left\{\chi_{t}\right\}$ of borrowing limits. Because the bond price and debt limits are deterministic, and there is a continuum of family members who face only idiosyncratic risk, the family's problem is deterministic.

The family values one unit of goods at date $t$ at the shadow price of $Q_{t}=\beta^{t} u^{\prime}\left(c_{t}\right) / u^{\prime}\left(c_{0}\right)$ units of date 0 goods. The Euler equation for consumption is

$$
q Q_{t}=Q_{t+1}+\theta_{t}
$$

where $\theta_{t}$ is the multiplier on the debt constraint. Hence, a tightening of debt constraints (a fall in $\chi_{t}$ ) raises the value of date $t$ consumption goods by forcing the family to repay its debt and thus cut consumption temporarily.

We next describe the second part of the family problem, which consists of firms' choices of vacancy creation and match creation and destruction, as well as consumers' values of employment and nonemployment.

\subsection{An Individual Firm's Problem}

We posit and then later characterize the equilibrium wages as the outcome of a (generalized) Nash bargaining problem that yields a wage $w=\omega_{t}(z, h)$. For a given wage $w$, the present value of profits earned by a firm matched with a worker with human capital levels $z$ and $h$, expressed in date 0 consumption units, is given by

$$
\tilde{J}_{t}(w, z, h)=Q_{t}(z h-w)+(1-\sigma) \phi \int \max \left[J_{t+1}\left(z^{\prime}, h^{\prime}\right), 0\right] d F_{e}\left(z^{\prime} \mid z\right)
$$

The flow profits are simply the difference between the amount $z h$ the firm produces and the wage $w$ it pays the worker. Since the firm is owned by the family, it values date $t$ profits using the family's shadow price $Q_{t}$. Given the function $w=\omega_{t}(z, h)$ from the Nash bargaining problem, the firm's value is defined as $J_{t}(z, h)=\tilde{J}_{t}\left(\omega_{t}(z, h), z, h\right)$.

The max operator on the right side of (7) reflects the option to destroy an unprofitable match. Let

$$
\psi_{t}(z, h)=1 \quad \text { if } \quad J_{t}(z, h) \geq 0
$$

denote matches that the firm chooses to continue and $\psi_{t}(z, h)=0$ denote matches that it chooses to destroy. Likewise, $\psi_{t}(z, 1)$ indicates whether a firm chooses to employ a newly matched worker. 


\subsection{An Individual Consumer's Values}

The consumer's value in any date depends on whether the consumer is employed or not. The present value of an employed consumer's earnings, expressed in date 0 consumption units, is

$$
\begin{aligned}
\tilde{W}_{t}(w, z, h)= & Q_{t} w+\phi(1-\sigma) \int \psi_{t+1}\left(z^{\prime}, h^{\prime}\right) W_{t+1}\left(z^{\prime}, h^{\prime}\right) d F_{e}\left(z^{\prime} \mid z\right) \\
& +\phi \int\left\{(1-\sigma)\left[1-\psi_{t+1}\left(z^{\prime}, h^{\prime}\right)\right]+\sigma\right\} U_{t+1}\left(z^{\prime}\right) d F_{e}\left(z^{\prime} \mid z\right),
\end{aligned}
$$

where general human capital evolves according to the law of motion $F_{e}\left(z^{\prime} \mid z\right)$ in (1) and firmspecific human capital evolves according to the law of motion in (3). The continuation value reflects the consumer's survival probability $\phi$, the exogenous separation probability $\sigma$, as well as the firm's choice of whether to continue a match next period, $\psi_{t+1}\left(z^{\prime}, h^{\prime}\right)$. If the match is dissolved for exogenous reasons or by the firm, the consumer enters the nonemployment state with a value of $U_{t+1}\left(z^{\prime}\right)$. Given the function $w=\omega_{t}(z, h)$ from the Nash bargaining problem, the consumer's value of working is defined as $W_{t}(z, h)=\tilde{W}_{t}\left(\omega_{t}(z, h), z, h\right)$.

The present value of a nonemployed consumer's earnings, expressed in date 0 consumption units, is

$$
\begin{aligned}
U_{t}(z)= & Q_{t} b(z)+\phi \lambda_{w t}(z) \int \psi_{t+1}\left(z^{\prime}, 1\right) W_{t+1}\left(z^{\prime}, 1\right) d F_{u}\left(z^{\prime} \mid z\right) \\
& +\phi \int\left\{\lambda_{w t}(z)\left[1-\psi_{t+1}\left(z^{\prime}, 1\right)\right]+1-\lambda_{w t}(z)\right\} U_{t+1}\left(z^{\prime}\right) d F_{u}\left(z^{\prime} \mid z\right) .
\end{aligned}
$$

Here $\lambda_{w t}(z)$, described further later, is the probability that a consumer with general human capital $z$ is matched with a firm at date $t$, in which case the consumer's state at $t+1$ consists of general human capital $z^{\prime}$ and firm-specific human capital $h^{\prime}=1$.

In both (9) and (10), we have used the implication of Nash bargaining that a firm employs a worker if, and only if, the worker prefers employment to nonemployment, that is, $\psi_{t+1}\left(z^{\prime}, h^{\prime}\right)=1$ if, and only if, $W_{t+1}\left(z^{\prime}, h^{\prime}\right) \geq U_{t+1}\left(z^{\prime}\right)$. The continuation value reflects the consumer's survival probability $\phi$, the consumer's matching rate $\lambda_{w t}(z)$, as well as the firm's choice of whether to not accept the match and employ the workers in the next period, $\psi_{t+1}\left(z^{\prime}, 1\right)$. In our quantitative analysis, most matches are indeed accepted.

Notice that the consumer matches with the firm at date $t$, but does not begin to work until date $t+1$, by which time the consumer's general human capital has evolved to $z^{\prime}$ according to the law of motion $F_{u}\left(z^{\prime} \mid z\right)$ for the unemployed, described in (2).

\subsection{Matching, Nash Bargaining, and Vacancy Creation}

We now consider the matching technology, the determination of wages through Nash bargaining, and the vacancy creation problem of firms. 
Matching. Firms can direct their search for consumers submarket by submarket, by posting vacancies for consumers of a given level of general human capital $z$. Let $u_{t}(z)$ be the measure of nonemployed consumers with human capital $z$ and $v_{t}(z)$ the corresponding measure of vacancies posted by firms for consumers in submarket $z$. The measure of matches in this submarket is generated by the matching function

$$
m_{t}(z)=u_{t}(z) v_{t}(z) /\left[u_{t}(z)^{\eta}+v_{t}(z)^{\eta}\right]^{\frac{1}{\eta}}
$$

as in den Haan, Ramey, and Watson (2000) and Hagedorn and Manovskii (2008). We use this matching function to ensure that job finding rates are between 0 and 1 . Specifically, the probability that a nonemployed consumer of type $z$ matches with a firm in submarket $z$ is then

$$
\lambda_{w t}(z)=m_{t}(z) / u_{t}(z)=\theta_{t}(z) /\left[1+\theta_{t}(z)^{\eta}\right]^{\frac{1}{\eta}},
$$

where $\theta_{t}(z)=v_{t}(z) / u_{t}(z)$ is the vacancy to nonemployment ratio for consumers of type $z$, and the parameter $\eta$ governs the sensitivity of $\lambda_{w t}(z)$ to $\theta_{t}$. The probability that a firm posting a vacancy in submarket $z$ matches with a consumer in this submarket is

$$
\lambda_{f t}(z)=m_{t}(z) / v_{t}(z)=1 /\left[1+\theta_{t}(z)^{\eta}\right]^{\frac{1}{\eta}} .
$$

Nash Bargaining. Consider next the Nash bargaining problem, which determines the wage $w=\omega_{t}(z, h)$ in any given match. The problem is

$$
\max _{w}\left[\tilde{W}_{t}(w, z, h)-U_{t}(z)\right]^{\gamma} \tilde{J}_{t}(w, z, h)^{1-\gamma},
$$

where $\gamma$ is a worker's bargaining weight. Defining the surplus of a match with a consumer with human capital $z$ as

$$
S_{t}(z, h)=W_{t}(z, h)-U_{t}(z)+J_{t}(z, h)
$$

Nash bargaining implies that firms and consumers split this surplus according to

$$
W_{t}(z, h)-U_{t}(z)=\gamma S_{t}(z, h) \text { and } J_{t}(z, h)=(1-\gamma) S_{t}(z, h) \text {. }
$$

Vacancy Creation. Consider finally the firm's choice of vacancy creation. The cost of posting a vacancy in any submarket $z$ is $\kappa$ units of goods. The free-entry condition in submarket $z$ is given by

$$
Q_{t} \kappa \geq \lambda_{f t}(z) \phi \int \max \left[J_{t+1}\left(z^{\prime}, 1\right), 0\right] d F_{u}\left(z^{\prime} \mid z\right)
$$


with equality if vacancies are created in submarket $z$ in that $v_{t}(z)>0$. Clearly, no vacancies are created in submarket $z$ if the value of expected profits conditional on matching is sufficiently low in that submarket. This occurs for all values of $z$ such that even if a vacancy leads to a match for a firm with probability 1 , expected profits are lower than the vacancy posting cost, that is, $Q_{t} \kappa>\phi \int \max \left[J_{t+1}\left(z^{\prime}, 1\right), 0\right] d F_{u}\left(z^{\prime} \mid z\right)$.

Since the surplus from a match increases with $z$, and the firm's value is proportional to the surplus, there is a cutoff level of general human capital $z_{t}^{*}$ such that firms post vacancies in all submarkets with $z \geq z_{t}^{*}$ and none in all submarkets with $z<z_{t}^{*}$.

\subsection{The Workings of the Model}

Here we provide some discussion about how our model works. We first describe the model's steady-state properties and then the responses to a debt tightening.

Steady State Properties. Panels A and B of Figure 1 display the steady-state measures of the employed $e(z)$ and nonemployed $u(z)$ as a function of general human capital, whereas panels $\mathrm{C}$ and D of this figure display the firm and consumer matching probabilities in submarket $z$. We generate these figures by using the parameter values described later.

As discussed, there is a cutoff level of $z$, say $z^{*}$, such that in submarkets $z<z^{*}$, firms post no vacancies and consumers have a zero matching probability. For $z<z^{*}$, even if a firm meets a consumer of type $z$ with probability 1 , the expected discounted stream of profits from such a match is below the vacancy posting cost $\kappa$. To the right of $z^{*}$, the consumer jobfinding probability increases with $z$. The reason is that firms matched with consumers with higher levels of $z$ earn higher profits and thus have greater incentives to post vacancies aimed at attracting such consumers. These incentives ensure that market tightness $v_{t}(z) / u_{t}(z)$ increases with $z$ and the firm matching probability falls with $z$ so that the expected value of posting a vacancy is the same in all active submarkets and equal to the cost of posting a vacancy.

Notice also that employed consumers have more general human capital on average than nonemployed consumers, for two reasons. First, there is a selection effect in that a consumer's job-finding probability increases with the consumer's general human capital. Second, on-thejob general human capital accumulation means that $z$ increases on average over time for employed consumers.

A Tightening of Debt Constraints. Consider next how a tightening of debt constraints affects firms' incentives to post vacancies and thus equilibrium employment. As we discuss later, such a tightening leads to a temporary decrease in the family's consumption as the 
family reduces its debt position to a new lower level. Hence, the debt tightening leads to a temporary increase in the family's marginal utility of consumption and thus the shadow price of goods $Q_{t}$. Because the drop in consumption is transitory, the sequence of shadow prices $Q_{t}, Q_{t+1}, Q_{t+2}, \ldots$, starts high and then reverts back to its steady-state level as consumption increases to its new steady-state level.

To understand how this temporary increase in the shadow price $Q_{t}$ affects firms' incentives to post vacancies, consider the free-entry condition. Since Nash bargaining implies that a firm's value is a constant fraction of match surplus, we can write the free-entry condition for active submarkets as

$$
Q_{t} \kappa=\lambda_{f t}(z) \phi(1-\gamma) \int \max \left[S_{t+1}\left(z^{\prime}, 1\right), 0\right] d F_{u}\left(z^{\prime} \mid z\right)
$$

Here the cost of posting vacancies on the left side is equal to the benefit, namely the product of the firm's matching probability $\lambda_{f t}(z)$, a decreasing function of market tightness $\theta_{t}(z)=$ $v_{t}(z) / u_{t}(z)$, and a term proportional to the expected surplus from a match.

The temporary increase in $Q_{t}$ has two effects on the free-entry condition. First, it raises the benefits of posting vacancies by increasing the expected surplus from a match. The surplus increases because a match produces a greater flow of output than does nonemployment, and the family values this net flow more when its consumption is lower. Second, a higher $Q_{t}$ directly raises the cost of posting vacancies, $Q_{t} \kappa$.

Importantly, the second effect dominates the first, so that the cost increases more than the benefit. The reason is that the cost is paid at $t$, when consumption is the lowest and goods are most valuable, but the benefits accrue in future periods when consumption is higher and thus goods are less valuable than they are at date $t$. Because the cost of posting vacancies increases more than the expected surplus from the match, the firm's matching probability $\lambda_{f t}(z)$ must increase after a debt tightening to ensure that the free-entry condition holds. Intuitively, firms post fewer vacancies because the cost of investing in new vacancies increases by more than the returns to such investments. This is a familiar effect from a large class of models in which a worsening of financial frictions leads to lower investment.

\section{Equivalence Results}

So far we have described a simple version of an economy with debt constraints. The labor market outcomes in the model, including employment, nonemployment, vacancies, and wages, are uniquely determined by the sequence of shadow prices $\left\{Q_{t}\right\}$. Because of this feature, there are many alternative setups for the family problem that yield equivalent outcomes for consumption and the associated shadow prices of goods and hence all labor market outcomes, 
although they may have different implications for other variables. To illustrate this point, we show the equivalence between our economy and two other economies: an economy with housing and an economy with illiquid assets.

In our economy with housing, debt is collateralized by the value of a house. Our equivalence result allows us to rationalize the drop in consumption and associated labor market outcomes in our baseline economy as actually driven by a tightening of collateral constraints arising from a fall in the price of housing, as many have argued.

In our economy with illiquid assets, consumers are net savers with the rest of the world rather than net borrowers as in our baseline model. Nevertheless, since savings are illiquid, a tightening of debt constraints reduces consumption because of liquidity constraints, as in the work of Kaplan and Violante (2014) on wealthy but liquidity-constrained households. Our equivalence result allows us to rationalize the drop in consumption and associated labor market outcomes in our baseline economy as arising in a model in which consumers are net savers.

These results make clear that for a large class of models, if the shocks produce the same paths for consumption as our simpler model, then they produce the same paths for labor market variables. In this sense, the robust link across models is the link between consumption and labor market outcomes, not the link between either house prices or levels of net asset positions and labor market outcomes. Motivated by these results, in our quantitative work we choose sequences of state-level shocks to reproduce the state-level consumption paths observed in the data and then study the corresponding labor market outcomes.

\subsection{An Economy with Housing}

Consider an economy in which families own houses and families' borrowing is subject to collateral constraints based on the value of their houses. The preferences of the family are

$$
\max _{c_{t}, h_{t+1}} \sum_{t=0} \beta^{t}\left[u\left(c_{t}\right)+\psi_{t} v\left(h_{t}\right)\right]
$$

where $c_{t}$ is the consumption of any of its members and $h_{t}$ is the amount of housing consumed in date $t$. The family faces a budget constraint,

$$
c_{t}+q a_{t+1}+p_{t} h_{t+1}=y_{t}+d_{t}+a_{t}+p_{t} h_{t}
$$

which is similar to that in (5) except that here a family owns a house of size $h_{t}$ with value $p_{t} h_{t}$ and chooses its next period's housing level $h_{t+1}$. Here, instead of facing the debt constraint (6), the family faces a collateral constraint that limits the amount it can borrow to a fraction $\bar{\chi}$ of the value of the family's house:

$$
a_{t+1} \geqslant-\bar{\chi} p_{t} h_{t+1},
$$


where $\bar{\chi}$ is the maximum loan-to-value ratio. The housing supply is fixed, and each unit of housing delivers one unit of housing services each period. The parameter $\psi_{t}$ in the utility function (13) governs the relative preference for housing. This parameter varies over time and is the source of changes in house prices and thus, through the collateral constraint, in the amount the family can borrow.

Let $\left\{Q_{t}\right\}$ denote the sequence of shadow prices that results from the debt constraint economy for some given sequence of debt constraints $\left\{\chi_{t}\right\}$. Clearly, there exists a sequence of taste parameters $\left\{\psi_{t}\right\}$ that gives rise to this same sequence of shadow prices in the economy with housing. Given these shadow prices, the search side of the economy with housing is identical to that of the economy with debt constraints. Hence, consumption, labor allocations, and wages in the two economies coincide. Likewise, given the sequence of shadow prices that results from the economy with housing, there exists a sequence of debt constraints in the debt constraint economy that gives rise to these same shadow prices. We show these results formally in the Appendix (online) and summarize this discussion with a proposition.

Proposition 1. The debt constraint economy is equivalent to the economy with housing in terms of consumption, labor allocations, and wages.

\subsection{An Economy with Illiquid Assets}

Here we consider an economy with illiquid assets. Each family can save in assets that have a relatively high rate of return but are illiquid and can borrow at a relatively low rate. The budget constraint is

$$
c_{t}+q_{a} a_{t+1}-q_{b} b_{t+1}=y_{t}+d_{t}+a_{t}-b_{t}-\phi\left(a_{t+1}, a_{t}\right)
$$

where $a_{t+1}$ denotes assets and $b_{t+1}$ denotes debt. We assume that $q_{a}=1 /\left(1+r_{a}\right)<q_{b}=$ $1 /\left(1+r_{b}\right)$ so that the return on assets, $1+r_{a}$, is higher than the interest on debt. We interpret $r_{a}$ and $r_{b}$ as after-tax interest rates. We imagine a situation in which even though the before-tax rate on debt is higher than on assets, the after-tax rate is lower due to the tax deductibility of interest payments. For simplicity, we assume that $\beta=q_{a}$. The function $\phi\left(a_{t+1}, a_{t}\right)$ represents the cost of adjusting assets from $a_{t}$ to $a_{t+1}$ and captures the idea that assets are illiquid. Borrowing is subject to the debt constraint

$$
b_{t+1} \leq \tilde{\chi}_{t}
$$

where $\left\{\tilde{\chi}_{t}\right\}$ is a sequence of exogenous maximal amounts of borrowing. The consumption

problem of the family is to choose $\left\{c_{t}, a_{t+1}, b_{t+1}\right\}$ to maximize the utility function in (4) subject to the budget constraint (15) and debt constraint (16). 
We assume that the interest rate on borrowing is sufficiently low in the illiquid asset economy that the borrowing constraint binds in the illiquid asset economy at the shadow prices constructed from the debt constraint economy. That is, condition

$$
q_{b}=\frac{1}{1+r_{b}}>\frac{Q_{t+1}}{Q_{t}}
$$

holds, where the right side of (17) is evaluated at the consumption allocations in the debt constraint economy. In the Appendix, we prove an analogous equivalence result to that in Proposition 1 that we summarize in the following proposition.

Proposition 2. Under (17), the debt constraint economy is equivalent to the economy with illiquid assets in terms of consumption, labor allocations, and wages.

\section{Quantification}

We next describe how we choose parameters for our quantitative analysis and the model's steady-state implications.

Assigned Parameters. The model is monthly. The utility function is $u\left(c_{t}\right)=c_{t}^{1-\alpha} /(1-\alpha)$. A large literature finds that the elasticity of intertemporal substitution is very low - on the order of 0.1 to 0.2 - when estimated using data on households. (See Guvenen (2006) and the references therein.) We follow this literature and set this elasticity, $1 / \alpha$, equal to 0.2 . We found that the responses of employment to a credit shock are approximately linear in the size of the shock: doubling the value of $\alpha$ would lead to doubling the employment responses. The discount factor $\beta$ is $(.96)^{1 / 12}$, the world bond price $q$ is $(.98)^{1 / 12}$, and the survival rate $\phi$ is set so that consumers are in the market for 40 years on average. The bargaining weight $\gamma$ is set to $1 / 2$. The separation rate $\sigma$ is set to $2.6 \%$ per quarter, in the mid-range of the estimates reported in Krusell et al. (2011). ${ }^{2}$ Home production is parameterized by $b(z)=b_{0}+b_{1} z$. We set the slope parameter $b_{1}$ equal to 0.25 and later discuss how we set the intercept $b_{0}$. It turns out that our results are not very sensitive to the choice of $b_{1}$.

Endogenously Chosen Parameters. We jointly choose the remaining parameters, $\vartheta=$ $\left(b_{0}, \eta, \kappa, \sigma_{z}, \rho, \bar{z}_{e}, \bar{h}\right)$, using the method of simulated moments by requiring that the model

\footnotetext{
${ }^{2}$ This figure is lower than the 3.6\% used by Shimer (2005) because Shimer includes job-to-job transitions, whereas we focus solely on employment-to-nonemployment transitions. We also experimented with a recalibration in which we used the higher separation rate from Shimer and found very similar results. As will become evident later, the employment responses in our model are determined by the duration of the benefit flows from a match, which is primarily influenced by the amount of general human capital accumulation of workers, rather than the length of time a worker spends attached to a particular firm.
} 
matches as closely as possible 10 moments. We can group these parameters into two sets: $\vartheta_{1}=\left(b_{0}, \eta, \kappa, \sigma_{z}\right)$ and $\vartheta_{2}=\left(\rho, \bar{z}_{e}, \bar{h}\right)$. For a given set of parameters $\vartheta_{2}$, the parameters in $\vartheta_{1}$ are pinned down by the following four moments: an employment-population ratio of 0.63, corresponding to the 2006 Current Population Survey estimate for people aged 16 and older; a job-finding rate of 0.45 from Shimer (2005); a vacancy cost as a fraction of monthly match output of 0.15 from Hagedorn and Manovskii (2008); and a standard deviation of wage changes in the Panel Study of Income Dynamics of 0.21, as in Floden and Linde (2001). Intuitively, the home production parameter $b_{0}$ is pinned down by the employment rate, the matching function elasticity $\eta$ is pinned down by the job-finding rate, the vacancy posting cost $\kappa$ is pinned down by the cost of posting a vacancy as a fraction of output, and the standard deviation of shocks $\sigma_{z}$ is pinned down by the volatility of changes in wages.

The parameters in $\vartheta_{2}$ determine how consumers accumulate human capital and are pinned down by moments that describe how wages grow on the job and over the life cycle. As we show later, the amount of on-the-job human capital accumulation is an important ingredient in the model's quantitative predictions. We therefore describe in detail how we quantify these parameters.

Parameters of Human Capital Processes. We quantify these parameters using moments and estimates derived from two sources of data on high school graduates: crosssectional data from Elsby and Shapiro (2012) on how wages increase with experience and longitudinal data from Buchinsky et al. (2010) on how wages grow during an employment spell. Later in our robustness analysis, we show that our results change little if we use alternative values for these moments and estimates.

The key moment we use from the cross-sectional data is the 1.21 difference in log wages between workers with 30 years of experience and those just entering the labor market. This difference corresponds to an average increase in wages of $4.1 \%$ per year of experience. This moment is calculated from the Elsby and Shapiro (2012) data on full-time workers from the census in years 1970, 1980, and $1990 .^{3}$

The five moments we use from the longitudinal data are those on how wages grow during an employment spell. These are calculated from the parameter estimates of the wage equation estimated by Buchinsky et al. (2010) using PSID data from 1975 to 1992 for high school graduates. These moments are the average annual growth rate of wages during an employment spell for workers with different levels of experience. These growth rates are equal to $10 \%$, $8 \%, 6 \%, 5 \%$, and $7 \%$ for workers with 1 to 10,11 to 20,21 to 30,31 to 40 , and 1 to 40 years

\footnotetext{
${ }^{3}$ Elsby and Shapiro (2012) use data on earnings. Since they focus on full-time workers working 35 or more hours per week for 50 or more weeks, we interpret their numbers as corresponding to wages in our model.
} 
of experience, respectively.

We turn to explaining how Buchinsky et al. (2010) estimate their wage equation and how we use their parameter estimates to quantify the parameters of our human capital process. Buchinsky et al. (2010) estimate a structural model of worker labor market participation, mobility decisions, and wages that allows for rich sources of heterogeneity. In particular, they estimate the parameters of an equation that relates workers' wages to their demographic characteristics and history of past employment, as well as current tenure (number of years with a given firm) and experience (number of years in the labor market). The equation describing an individual $i$ 's wages at date $t$ is

$$
\log w_{i t}=z_{i t}^{\prime} \beta+f\left(\text { experience }_{i t}\right)+g\left(\text { tenure }_{i t}\right)+\varepsilon_{i t},
$$

where $z_{i t}$ captures individual characteristics as well as the history of that individual's past employment. The functions $f(\cdot)$ and $g(\cdot)$ are fourth-order polynomials in experience and tenure.

We use the parameter estimates from (18) as follows. For a given parameterization $\vartheta$ of our model, we simulate paths for wages, experience, and tenure for a panel of individuals. Given the simulated experience and tenure profiles from our model, we compute the annualized wage growth predicted by (18). The last five moments we use to calibrate our model are the predicted growth rates for the five experience groups listed earlier. We choose parameters so that in our model wages grow during an employment spell at the same rates as those implied by the Buchinsky et al. (2010) estimates for workers with different levels of experience.

We show later in our robustness analysis that our model's implications for the labor market responses to a credit tightening are robust to using alternative evidence on how wages grow over the life cycle from Rubinstein and Weiss (2006) and how wages grow on the job from Altonji and Shakotko (1987) and Topel (1991).

Intuition for Identification. We now provide some intuition for how we separately identify the parameters $\left(\rho, \bar{z}_{e}, \bar{h}\right)$ governing general and firm-specific human capital accumulation. While increases in $\bar{z}_{e}$ and $\bar{h}$ lead to similar increases in on-the-job wage growth, an increase in $\bar{z}_{e}$ leads to a much larger increase in life-cycle wage growth than does an increase in $\bar{h}$. The reason is twofold: firm-specific human capital is lost after each transition into nonemployment, whereas general human capital is not, and workers typically experience multiple employment and nonemployment spells over their lifetimes. Finally, a decrease in $\rho$ makes the wages of young workers grow faster than the wages of older workers and, hence, helps the model account for the differential on-the-job wage growth of workers with different levels of experience. Hence, the combination of the cross-sectional evidence in Elsby and Shapiro 
(2012) and the longitudinal evidence summarized by the Buchinsky et al. (2010) parameter estimates jointly identifies these three parameters.

Recall that the cross-sectional evidence shows that life-cycle annual wage growth is equal to $4.1 \%$, whereas the longitudinal data imply an overall on-the-job wage growth of $7 \%$. To understand how the model can simultaneously account for these two facts, consider Figure 2 , which shows the path of wages of a typical worker in our model. This worker experiences several employment and nonemployment spells over the life cycle and, for simplicity, no shocks to human capital. Note that wages drop after each transition into nonemployment, owing to the loss in firm-specific human capital. Thus, even though wages rise relatively rapidly on the job, they rise less rapidly over the life cycle, due to the wage declines associated with transitions into nonemployment. As we discuss later, our model's implications for the loss in wages after a transition into nonemployment are in line with the data.

Summary and Additional Implications. Table 1, panels A and B, summarizes our parameterization strategy: it shows the moments used in our calibration, the parameters that we assign, and those that we endogenously choose. As Table 1 shows, the model exactly matches the first set of four moments that pin down the parameters in $\vartheta_{1}$ and closely reproduces the remaining wage growth moments that pin down the parameters in $\vartheta_{2}$. Table 1 , panel $\mathrm{B}$, also reports the implied parameter values. Notice that the parameter $b_{0}$ that determines how much nonemployed consumers produce is about $42 \%$ of the average amount produced by employed consumers. The parameter governing the drift of general human capital accumulation, $\log \bar{z}_{e}$, is equal to 2.44 , whereas that governing firm-specific human capital accumulation, $\log \bar{h}$, is equal to 0.82 .

To see what our parameter estimates imply about the relative importance of the two types of human capital, consider an alternative version of the model in which firm-specific human capital is constant at $\bar{h}=1$ and the other parameters are unchanged. The resulting model generates an average annual on-the-job wage growth of $5 \%$, thus about $1 / 3$ lower than that implied by our baseline model, but it implies a difference in the log wages of workers with 30 years of experience and workers just entering the labor market of 1.02, which is only slightly lower than the 1.19 difference implied by the baseline model. Taken together, these numbers imply that firm-specific human capital accumulation accounts for about $1 / 3$ of on-the-job wage growth but for only $16 \%$ of life-cycle wage growth.

Table 2 shows additional steady-state implications of the model for moments not explicitly targeted in our calibration. Recall from Table 1 that $37 \%$ of consumers in our model are not working. As Table 2 shows, however, only $4 \%$ of the consumers who are not working have a positive job-finding rate. For this last group, as Table 1 shows, the average job-finding rate 
is $45 \%$ per month on average. Heterogeneity in job-finding rates thus allows our model to simultaneously replicate the large number of nonemployed in the data and the modest flows out of nonemployment into employment.

As Table 2 also shows, the average amount produced by nonemployed consumers is about $48 \%$ of the average wage of employed consumers, in the mid-range of typical parameterizations of the DMP model. To put this number into perspective, recall that the corresponding number in Shimer (2005) is 40\% and that in Hagedorn and Manovskii (2008) is 96\%. Endogenous separations occur infrequently and account for only $0.02 \%$ of all separations. The standard deviation of log wages in the cross section of employed consumers is equal to 0.82 , only slightly less than the range of numbers reported by Song et al. (forthcoming). The profit share of revenue is $6 \%$, in line with the estimates of the profit share in the aggregate U.S. data. The average drop in wages after a nonemployment spell is $5 \%$, a number in line with the estimate of $5.6 \%$ we obtain using the PSID sample of Buchinsky et al. (2010).

\section{Response of Employment to a Tightening of Credit}

We next illustrate how employment responds to a tightening of credit and then explain the role of human capital accumulation and consumer-side credit frictions in accounting for this response.

\subsection{Impulse Responses to a Tightening of Credit}

To build intuition for how the model works, we conduct an experiment in which we assume an unanticipated tightening of the debt constraint. We describe the response of consumption and employment, decompose the drop in employment into the components arising from the overall job-finding rate and separation rate, and then discuss why the drop in employment is persistent.

The Response of Employment and Consumption. We assume that this credit tightening is unexpected prior to the first period and that consumers have perfect foresight afterward. We choose a sequence of debt limits $\left\{\chi_{t}\right\}$ so that consumption drops by $5 \%$ on impact and then reverts to its original steady state at a rate of $10 \%$ per quarter. This mean-reversion rate is chosen so as to match the speed of postwar consumption recoveries in the data. The shadow price $Q_{t}$ increases proportionately to the drop in consumption and reverts to its original steady state at the same rate as consumption.

Figure 3 displays the path for employment relative to that of consumption in this experiment. The $5 \%$ fall in consumption is accompanied by a $2.7 \%$ maximal drop in employment. 
Note that the drop in employment is gradual because, as we show later, it is driven mainly by a drop in the job-finding rate, rather than by an increase in the separation rate: declines in the job-finding rate reduce the flow of consumers out of nonemployment and therefore only slowly reduce the stock of employed consumers.

The Shimer Decomposition of Employment. We next shed light on the mechanism behind the impulse response for employment. The drop in employment is due to the combination of the drop in the job-finding rates and the increase in the endogenous component of separation rates. Quantitatively, the main force leading to the decline in employment is the decline in the job-finding rates.

To quantify the importance of these two factors in accounting for the employment drop, we build on the approach in Shimer (2012). Note that the transition law for total employment can be written as $e_{t+1}=\left(1-s_{t}\right) e_{t}+f_{t}\left(1-e_{t}\right)$, where $e_{t}$ is the overall employment rate; $s_{t}$ is the overall separation rate, equal to the sum of exogenous and endogenous separations; and $f_{t}$ is the overall job-finding rate. We construct two counterfactual employment series in which we vary $s_{t}$ and $f_{t}$ one at a time while leaving the other at its steady-state value.

In Figure 4 we see that the component of the employment drop arising from the change in the separation rate accounts for a small part of the initial drop in employment. The reason is that the separation rate increases a bit on impact, because firms find it optimal to dissolve marginal matches. The vast bulk of the decline in employment, however, is due to the decline in the job-finding rate. As we discussed earlier, the job-finding rate falls because posting vacancies requires paying an up-front cost at a time when consumption is especially low and hence goods are especially valuable, namely in the immediate aftermath of the credit tightening. In contrast, the benefits to posting vacancies accrue gradually over time when consumption recovers. The family's desire to smooth consumption thus leads to a drop in investment in vacancy creation and thus employment.

The Persistent Drop in Employment. Note that the employment drop in our model is more persistent than the consumption drop. One way to see this is to note that even though on impact the fall in employment is lower than that in consumption, the cumulative impulse response of employment in the first four years is 0.9 times as large as that of consumption.

The employment drop is persistent because of an endogenous deterioration of the general human capital of nonemployed consumers along the transition. Since employment produces human capital, the initial drop in employment leads to a persistent reduction in the overall amount of human capital in the economy and, thus, to a worsening of the skill levels of the nonemployed. The average skill levels of the nonemployed return to their steady-state 
values only gradually. Hence, even after the shadow price $Q_{t}$ has returned to its steady state, firms post fewer vacancies because the average nonemployed consumer is less productive and, hence, makes for a less profitable match.

A simple moment that illustrates this worsening of the skill level of the nonemployed is the productivity of the median active nonemployed consumer at any point in time. Figure 5 shows that while on impact this productivity level increases because of the spike in the separation rate of workers, it decreases in a persistent way over time. Even 10 years after the initial credit tightening, the median productivity level is still $3 \%$ below its steady-state value. Productivity falls because the entire distribution of nonemployed workers drifts to the left. This drift is due to consumers spending less time employed during the downturn and, hence, accumulating less human capital.

Notice that, in contrast to the standard DMP search model, this novel propagation mechanism allows our model to generate a reduction in employment that is more persistent than the underlying shock and can help account for the scarring effects of recessions.

\subsection{Key Ingredients of Our Model}

We have introduced two ingredients in an otherwise standard search and matching model: on-the-job human capital accumulation and debt constraints that affect consumer-side and firm-side valuations. We argue next that each of these ingredients is critical in generating sizable employment responses to a credit crunch.

On-the-Job Human Capital Accumulation. Consider first the role of on-the-job human capital accumulation. We compare the implications of our model with those of an alternative model with no growth in either general or firm-specific human capital in which we set $\bar{z}_{e}=1$ and $\bar{h}=1$. We choose the four parameters in $\vartheta_{1}$ in this version of the model to ensure that the model exactly reproduces the first four moments in panel A of Table 1 . Since credit market conditions can be summarized by their effect on the shadow prices $\left\{Q_{t}\right\}$, we choose the amount of credit tightening in this version of the model to generate the same path for these shadow prices as in the baseline model.

Figure 6 shows that in the economy without human capital accumulation, employment responds very little to the debt tightening: it falls by only about one-tenth of the amount it does in our baseline model. (Notice that although this model has no growth in general human capital $z$, it features heterogeneity in $z$ because of the shocks to human capital accumulation. We also considered a simpler version of the model without such heterogeneity, in which all consumers have the same fixed level of general human capital, and found similar results.)

We next provide some intuition for this result by examining the firm's incentives to post 
vacancies in the two versions of the model. As the earlier discussion of the workings of the model made clear, the size of the fall in employment depends on the relative size of the increase in the cost of posting vacancies, $Q_{t} \kappa$, and the increase in the expected surplus from a match.

Since the increase in the cost of posting vacancies is the same in the two models, the key to understanding the different responses is the differential increase in the surplus from a match in the two models. Since the shadow price $Q_{t}$ increases the most immediately and then mean reverts, the amount by which surplus increases depends on when exactly the returns to a match accrue. In the model without human capital accumulation, these returns accrue almost immediately after the credit tightening, and hence their valuation increases almost as much as $Q_{t}$ does. In contrast, in the model with human capital accumulation, these returns accrue gradually over time, and hence their valuation increases much less than $Q_{t}$ does.

To understand precisely why the timing of when the flow surplus is accrued matters, write the free-entry condition for a given submarket $z$ as

$$
Q_{t} \kappa=\lambda_{f t}(z) \times\left[Q_{t+1} s_{t+1}(z)+Q_{t+2} s_{t+2}(z)+Q_{t+3} s_{t+3}(z)+\ldots\right],
$$

where $s_{t+j}(z)$ is the component of the expected flow surplus produced by this match that accrues in date $t+j$. The expectation takes into account all the uncertainty concerning this match, including the possibility that a match dissolves because of death or exogenous separations, and the shocks to general human capital. (See the Appendix for details on how we compute these components.)

After a credit tightening at date $t$, the cost of a match, given by the left side of (19), increases one-for-one with $Q_{t}$. Consider next the surplus from a match, given by the term in brackets on the right side of (19). In the model without human capital accumulation, most of the returns from a match accrue in the first few periods after the match is formed. To see this, consider the standard measure of how long-lived the flows from an investment are, namely, the Macaulay duration. This duration is given by $\sum_{k=1}^{\infty} k \omega_{k}$, where $\omega_{k}$ is the fraction of the present value of the flow of benefits accrued $k$ periods after the investment is made. Here,

$$
\omega_{k}=\frac{Q_{t+k} s_{t+k}(z)}{Q_{t+1} s_{t+1}(z)+Q_{t+2} s_{t+2}(z)+Q_{t+3} s_{t+3}(z)+\ldots} .
$$

In the model without human capital, this duration is equal to 2.8 months on average, so that the returns to a match accrue quickly. During the first few months following a credit tightening, $Q_{t}$ has not reverted much to its mean, and hence the surplus increases almost as much as the cost and, thus, employment falls little.

In contrast, in the model with human capital accumulation, the returns to a match are long-lived. A similar calculation shows that the Macaulay duration is equal to almost 10 
years on average. Since the shadow price $Q_{t}$ mean reverts after only a few years, the present value of these benefits flows from a match, given by the term in brackets on the right side of (19), increases by much less than the cost. Hence, firms post many fewer vacancies and employment falls a lot.

We next explain why the textbook model without human capital accumulation implies such short durations of benefit flows from a match. We do so by setting $\bar{h}=1$, so there is no firm-specific human capital accumulation, and by setting $F_{e}\left(z^{\prime} \mid z\right)$ equal to $F_{u}\left(z^{\prime} \mid z\right)$, so that there is no general human capital accumulation on the job. When we do so we can write the expression for match surplus recursively as

$$
S_{t}(z)=Q_{t}[z-b(z)]+\left[1-\sigma-\lambda_{w t}(z) \gamma\right] \phi \int \max \left[S_{t+1}\left(z^{\prime}\right), 0\right] d F\left(z^{\prime} \mid z\right)
$$

where $F\left(z^{\prime} \mid z\right)$ is the common law of motion of human capital among employed and nonemployed consumers. This expression, familiar from the textbook model, is simply the discounted sum of the difference between what a consumer produces when employed, $z$, and when not employed, $b(z)$. As is well understood, the return from a match accrues almost immediately in the textbook model because it is discounted by the factor $1-\sigma-\lambda_{w t}(z) \gamma$, which is low due to the relatively high separation, $\sigma$, and job-finding probabilities, $\lambda_{w t}$, in the data. Intuitively, the fact that these probabilities are high implies that an employed consumer produces more output than a nonemployed consumer for only a few months on average. Hence, the duration of benefit flows is very short.

Consider next why our model with human capital accumulation implies such long durations of benefit flows from a match. Here, match surplus can be written recursively as

$$
\begin{aligned}
S_{t}(z, h)= & Q_{t}[z h-b(z)]+\left[1-\sigma-\lambda_{w t}(z) \gamma\right] \phi \int \max \left[S_{t+1}\left(z^{\prime}, h^{\prime}\right), 0\right] d F_{e}\left(z^{\prime} \mid z\right) \\
& +\phi \int U_{t+1}\left(z^{\prime}\right)\left[d F_{e}\left(z^{\prime} \mid z\right)-d F_{u}\left(z^{\prime} \mid z\right)\right] \\
& +\lambda_{w t}(z) \gamma \phi\left[\int \max \left[S_{t+1}\left(z^{\prime}, h^{\prime}\right), 0\right] d F_{e}\left(z^{\prime} \mid z\right)-\int \max \left[S_{t+1}\left(z^{\prime}, 1\right), 0\right] d F_{u}\left(z^{\prime} \mid z\right)\right],
\end{aligned}
$$

where the value of a nonemployed consumer is

$$
U_{t}(z)=Q_{t} b(z)+\lambda_{w t}(z) \gamma \phi \int \max \left[S_{t+1}\left(z^{\prime}, 1\right), 0\right] d F_{u}\left(z^{\prime} \mid z\right)+\phi \int U_{t+1}\left(z^{\prime}\right) d F_{u}\left(z^{\prime} \mid z\right)
$$

Equation (21) shows that the surplus from a match is the sum of two components. The first component, given by the right side in the first line of (21), is essentially identical to that in the model without human capital accumulation. The second component comes from the second and third lines in (21) and reflects human capital accumulation. Since human capital grows faster when the consumer is employed, the surplus also includes the difference 
between the two laws of motion of general human capital accumulation for employed and nonemployed consumers, $d F_{e}\left(z^{\prime} \mid z\right)-d F_{u}\left(z^{\prime} \mid z\right)$, as well as the difference between firm-specific human capital $h^{\prime}$ for continuing matches and new matches, $h=1$. Since general human capital is transferable across matches, the general human capital earned in the current match will be used by the consumer in all of its future matches. Hence, this component of match surplus is long-lived.

Consumer-Side Credit Frictions. A second key ingredient of our model is that a debt tightening at the level of the family acts like a simultaneous tightening of both firm-side and consumer-side credit frictions. This ingredient is not present in a sizable literature in macroeconomics that focuses solely on the effect of firm-level credit frictions. We next conduct an experiment that shows that consumer-side credit frictions are critical to generating the large drop in employment in our baseline model.

To isolate the effects of consumer-side credit frictions from firm-side credit frictions, we allow the shadow prices in the consumer and firm problem to differ. Let $Q_{c t}$ denote the shadow price in the consumer's problem (9) and (10), and let $Q_{f t}$ denote the shadow price in the firm's problem (7). We then conduct a credit tightening experiment on the firm side only, by keeping $Q_{c t}$ unchanged at $q^{t}$ and letting $Q_{f t}$ follow the same path as $Q_{t}$ in our baseline model.

One interpretation of this experiment is that the economy consists of two types of families. One type of families has consumers who supply labor but own no firms, have discount factors $\beta=q$, and face no debt constraint. The second type of families consists of entrepreneurs who supply no labor and earn income only through their ownership of firms. We imagine a credit tightening that reduces the consumption of entrepreneurs and thus increases their shadow price $Q_{f t}$ by the same amount by which we increased $Q_{t}$ in our baseline model.

Figure 7 shows that such a firm-side credit tightening leads to only a modest drop in employment, less than 1/10 that in our baseline model. To see why this is the case, note that when firms and consumers have different marginal valuations of goods, the Nash bargaining solution implies a surplus sharing rule of the form

$$
J_{t}=\frac{(1-\gamma) Q_{f t}\left(W_{t}-U_{t}\right)}{\gamma Q_{c t}}
$$

Thus, when a firm's shadow price increases but a consumer's does not, the fraction of match surplus received by the firm increases, thus offsetting the increased cost of posting vacancies. In equilibrium, wages fall a lot in this version of the model, thus insulating firms from adverse credit conditions. In contrast, in our baseline model, $Q_{c t}$ and $Q_{f t}$ increase proportionately, since both firms and consumers are effectively subject to debt constraints. This proportional 
increase prevents wages from falling too much, thus leading to a much larger drop in vacancies and employment.

We think of this experiment as a way to decompose the effect of the two sides of credit frictions in our baseline model, rather than as an interesting alternative to that model. The reason is that we interpret Mian and Sufi $(2011,2014)$ as having documented the importance of consumer-side credit frictions and Giroud and Mueller (forthcoming), among many others, as having documented the importance of firm-side credit frictions during the Great Recession. To be consistent with these observations, our model has both consumer-side and firm-side credit frictions.

\subsection{Robustness to Alternative Estimates of Wage Growth}

In our quantification of the human capital processes, we have used estimates of wage growth based on Elsby and Shapiro (2012) and Buchinsky et al. (2010). The literature has provided a range of such estimates. Here we show that our results on how the economy responds to a credit tightening are robust to using alternative estimates. We then report how our results change for a wide range of values for the parameters governing the rate of human capital accumulation.

Alternative Estimates of Wage Growth. Consider first how wages increase with experience in the cross section. Recall that Elsby and Shapiro (2012) document that the wage differential between workers with 30 years of experience and those entering the labor market is $1.21 \log$ points. In contrast, Rubinstein and Weiss (2006) report a range of values for this wage differential centered around $0.80 \mathrm{log}$ points. In the two robustness experiments that follow, we target this lower wage differential.

Consider next the estimates of on-the-job wage growth. Whereas the Buchinsky et al. (2010) estimates of the wage equation in (18) imply an average on-the-job wage growth of $7 \%$ per year, the earlier literature finds smaller numbers. Accordingly, we consider two alternative parameterizations derived from the estimated wage equations of the influential studies of Altonji and Shakotko (1987) and Topel (1991).

As earlier, for a given parameterization of our model, we simulate paths for wages, experience, and tenure for a panel of individuals. Given the simulated experience and tenure profiles from our model, we compute the annualized wage growth predicted by the estimated wage equations in Altonji and Shakotko (1987) and Topel (1991). We then choose parameters in our model to ensure that our model's implications for wage growth at various levels of experience are consistent with the implications of these estimates.

Table 3A shows the moments from the data and the model for these alternative sets of 
estimates. For simplicity, we refer to the first robustness experiment that uses estimates of the parameters of wage growth from Altonji and Shakotko (1987) as the Altonji-Shakotko experiment, and refer to the second robustness experiment that uses estimates of the parameters of wage growth from Topel (1991) as the Topel experiment. The first five moments are common to both experiments. In particular, we use the cross-sectional log-wage differential from Rubinstein and Weiss (2006, Figure 3a, page 9), as well as the employment rate, jobfinding rate, vacancy posting cost, and standard deviation of wage changes from our baseline model.

Notice that we match all of these moments almost perfectly. Importantly, on-the-job wage growth rates are now substantially smaller than in our baseline model. For example, the average on-the-job wage growth for workers with 1 to 40 years of experience is $7 \%$ in our baseline model but only $3 \%$ in the Altonji-Shakotko experiment and $5 \%$ in the Topel experiment.

Table 3B shows the resulting parameter values and compares them with those in the baseline model. Notice that the parameters governing the rate of human capital accumulation $\bar{z}_{e}$ and $\bar{h}$ are substantially smaller in these two robustness experiments than in our baseline model. Nevertheless, both of these alternatives imply a sizable amount of general human capital accumulation, as indicated by $\log \bar{z}_{e}$ being substantially greater than 0 . In these experiments, all other parameters, which are chosen with the method of simulated moments, adjust appropriately for the model to replicate all remaining targeted moments.

Figure 8 shows how employment responds to a debt tightening that leads to the same $5 \%$ drop in consumption as in our baseline model. Note that the maximal drop in employment is slightly larger than in our baseline: it is $2.7 \%$ in our baseline and about $3 \%$ in both of these alternative experiments. Also note that both of these alternative experiments predict that the employment drop is very persistent. In particular, the cumulative impulse response of employment relative to that of employment after four years is 0.91 in the Altonji-Shakotko parameterization and 0.98 in the Topel parameterization, which are both larger than the corresponding 0.9 statistic in the baseline parameterization.

So far we have focused on estimates of life-cycle wage growth and on-the-job wage growth for high school graduates. We also repeated our exercise for analogous estimates from Elsby and Shapiro (2012) and Buchinsky et al. (2010) for individuals with less than a high school education and for individuals with a college education. We found that for both sets of estimates, the maximal employment drop and the cumulative employment drop were similar to those in our baseline model.

We thus conclude that our results are robust to alternative estimates of wage growth in the literature. 
Results for a Wide Range of Parameter Values. So far we have shown that our model's implications for how employment responds to a credit tightening are robust to a range of estimates of cross-sectional wage-experience profiles and on-the-job wage growth reported in the literature. In Figure 9 we vary the parameters $\log \bar{z}_{e}$ and $\log \bar{h}$ governing the rate of general and firm-specific human capital accumulation in a wider region of the parameter space and present the model's implications for wage growth and the response of employment to a credit tightening. We show that as long as $\log \bar{z}_{e}$ is above a threshold consistent with a lifecycle wage growth of $1.5 \%$ per year, the model's implications for employment are virtually identical. As earlier, when we vary these parameters, all other parameters, chosen with the method of simulated moments, adjust appropriately for the model to replicate all other statistics.

Panels A and B of Figure 9 report the model's implications for wage growth on the job and over the life cycle in these experiments. The lines marked with triangles set $\bar{h}$ equal to our baseline value, whereas the lines marked with circles eliminate all firm-specific human capital accumulation by setting $\bar{h}$ equal to 1 . As we vary $\bar{z}_{e}$, the model produces a wide range of rates of wage growth over the life cycle and on the job. Also note, as we discussed earlier, that cross-sectional wage-experience profiles vary little with the amount of firm-specific human capital accumulation, in that the two lines in panel B are essentially on top of each other.

Consider next the models' implications for how employment responds to a credit tightening. We summarize these implications in panels $\mathrm{C}$ and $\mathrm{D}$ with two statistics: the maximal employment drop after a 5\% drop in consumption and the cumulative drop in employment relative to consumption in the first four years after the tightening.

Notice from these figures that as long as the drift parameter of general human capital, $\log \bar{z}_{e}$, is greater than 1, our model's key predictions for employment responses are remarkably similar. In particular, the maximal employment drop is about $2.7 \%$ to $3 \%$, whereas the cumulative drop is about 0.9 that of consumption in the first four years after the tightening. Figure 9 shows that we would have obtained similar employment responses even if we had chosen parameters of general and firm-specific human capital to imply an on-the-job wage growth as low as $2 \%$ per year and a differential between the wages of workers with 30 years of experience and no experience of $0.45 \log$ points - namely, by setting $\log \bar{z}_{e}$ slightly less than 1 and $\log \bar{h}=0$. For these parameter values, life-cycle wage growth is equal to $1.5 \%=0.45 / 30$ per year.

As the panels $\mathrm{C}$ and $\mathrm{D}$ show, however, if there were no growth at all in either general or firm-specific human capital, our model would produce negligible employment responses. But, interestingly, once we allow for even modest growth in general human capital, our model produces similar employment responses. 
We next provide some intuition for why the employment responses are nonlinear in the rate of general human capital accumulation. Part of the intuition can be obtained by realizing that the duration of benefit flows is nonlinear in the rate of human capital accumulation. Figure 10 shows how the duration varies as we vary the drift parameter $\log \bar{z}_{e}$. This figure makes clear that duration is highly concave in the drift parameter: as this parameter increases, the marginal effects on duration decrease and duration asymptotes to about 130 months. Intuitively, the combination of a consumer's finite lifetime, the positive separation rates from a firm, and the relatively high job-finding rates for nonemployed consumers gives rise to an upper bound on how long-lived are the benefit flows to a match.

The rest of the intuition is that when we consider a mean-reverting increase in the shadow prices of goods, the benefit flows received after some date in the future barely increase in their valuation, regardless of how distant they are. This explains why employment responses are even more concave in $\bar{z}_{e}$ than is duration.

\section{An Economy with Tradable and Nontradable Goods}

Our one-good model discussed earlier is useful for illustrating the essential ideas behind the workings of our new mechanism. We next evaluate the ability of this mechanism to account for the cross-state evidence in the United States during the Great Recession on the comovement of consumption, employment, and wages. To do so, we embed the labor market structure of the one-good model into a richer model with tradable and nontradable goods. Importantly, this richer model has identical steady-state implications for labor market variables and human capital accumulation as the one-good model and can thus match both the cross-sectional and longitudinal evidence on how wages grow over the life cycle and during an employment spell.

We discuss the evidence from a cross section of U.S. states, develop the richer version of our model, and then present our main quantitative findings. We show that our richer model reproduces well the key cross-state patterns.

\subsection{Motivating Evidence from U.S. States}

Our work is motivated by several patterns that are closely related to those documented by Mian and Sufi (2014) and Beraja, Hurst, and Ospina (2016) for a cross section of U.S. regions.

The first pattern is that regions of the United States with the largest declines in consumption experienced the largest declines in employment, especially in the nontradable goods sector. The second observation is that regions with the largest employment declines experienced the largest declines in real wages relative to trend.

Here we illustrate the first pattern by using annual data on employment and consumption 
from the Bureau of Economic Analysis (BEA) for U.S. states. We provide a brief description of the data and provide more detail in the Appendix. Employment is measured as total statelevel private nonfarm employment, excluding construction, relative to the total state-level working-age population. We exclude construction since our model abstracts from housing investment. We follow the BEA classification of sectors to break down overall employment into nontradable and tradable employment. We measure consumption as real per capita consumption expenditure in each state. In the spirit of the model, we isolate changes in consumption triggered by changes in households' ability to borrow, or more generally in credit conditions, as proxied by changes in house prices. To isolate this component, we project state-level consumption growth on the corresponding growth in state-level (Zillow) house prices, and use the resulting series for consumption growth in our analysis. See Charles, Hurst, and Notowidigdo (2015) for a similar approach.

In panel A of Figure 11, we plot state-level employment growth between 2007 and 2009 against state-level consumption growth over this same period. The figure shows that the elasticity of employment to consumption is 0.38 ; that is, a $10 \%$ decline in consumption is associated with a $3.8 \%$ decline in employment.

Panels $\mathrm{B}$ and $\mathrm{C}$ show that consumption declines are associated with relatively large declines in nontradable employment and essentially no changes in tradable employment: a $10 \%$ decline in consumption across states is associated with a 5.5\% decline in nontradable employment and a negligible (and statistically insignificant) $0.3 \%$ increase in tradable employment. As the large negative intercept in the figure shows, the decline in tradable employment is large in all states but unrelated to changes in state-level consumption across states.

Now consider the second observation. Beraja, Hurst, and Ospina (2016) also interpret the cross-regional variation in employment as arising from shocks that lead to differential consumption declines across states. They document that states that experienced the largest employment declines experienced the largest decline in real wages relative to trend.

Here we reproduce a version of their findings. For wages we use data from the Integrated Public Use Microdata Series, and we control for observable differences in workforce composition both across states and within a state over time, closely following the approach in Beraja, Hurst, and Ospina (2016). We show in panel D that a decline in employment of $10 \%$ across states is associated with a decline in wages of 7.8\%. As Beraja, Hurst, and Ospina (2016) argue, in this sense, in the cross section wages are moderately flexible.

In sum, state-level data show that consumption, employment, and real wages all strongly positively comove. We summarize these comovements in the first column of Table 4. 


\subsection{The Richer Model with Tradable and Nontradable Goods}

Here we extend our economy to one that can address the cross-state evidence just discussed. We first present the setup of the model and then the results from our quantitative experiments. Most of the details of the model are identical to those of the one-good model and are omitted for brevity. We only discuss the additional ingredients that we introduce.

The economy consists of a continuum of islands, each of which produces intermediate goods, which are combined to make nontradable goods that are only consumed on the island, and a differentiated variety of tradable goods that are consumed everywhere. Consumers receive utility from a composite good that is purchased in the market or produced at home. Each consumer is endowed with one of two types of skills. Labor is immobile across islands but can switch sectors. We let $s$ index an individual island.

In our experiments, we consider shocks to only a subset of islands that, taken together, are small in the world economy and borrow from the rest of the world at a constant bond price $q>\beta$. In our simple interpretation, this subset of islands is a net borrower from the rest of the world. Of course, given our earlier equivalence results, there are alternative interpretations of these experiments, such as the illiquid asset interpretation, in which the subset of the islands we consider is not a net borrower from the rest of the world.

Preferences and Demand. The composite consumption good on island $s$ is produced from nontradable goods on island $s$ and tradable goods according to

$$
x_{t}(s)=\left[\tau^{\frac{1}{\mu}}\left(x_{N t}(s)\right)^{1-\frac{1}{\mu}}+(1-\tau)^{\frac{1}{\mu}}\left(x_{M t}(s)\right)^{1-\frac{1}{\mu}}\right]^{\frac{\mu}{\mu-1}} .
$$

The demand for nontradable goods and tradable goods on island $s$ is given by

$$
x_{N t}(s)=\tau\left(\frac{p_{N t}(s)}{p_{t}(s)}\right)^{-\mu} x_{t}(s) \text { and } x_{M t}(s)=(1-\tau)\left(\frac{p_{M t}}{p_{t}(s)}\right)^{-\mu} x_{t}(s),
$$

where $p_{N t}(s)$ is the price of nontradable goods, $p_{M t}$ is the world price of tradable goods, and

$$
p_{t}(s)=\left[\tau\left(p_{N t}(s)\right)^{1-\mu}+(1-\tau) p_{M t}^{1-\mu}\right]^{\frac{1}{1-\mu}}
$$

is the price of the composite good on island $s$.

The tradable good itself is a composite of varieties of differentiated goods produced in all other islands $s^{\prime}$, given by

$$
x_{M t}(s)=\left(\int x_{M t}\left(s, s^{\prime}\right)^{\frac{\mu_{X}-1}{\mu_{X}}} d s^{\prime}\right)^{\frac{\mu_{X}}{\mu_{X}-1}},
$$

where $x_{M t}\left(s, s^{\prime}\right)$ is the amount of the island $s^{\prime}$ variety of tradable goods consumed on island $s$ and $\mu_{X}$ is the elasticity of substitution between varieties produced on different islands. We 
assume that there are no costs of shipping goods from one island to another so that the law of one price holds and all islands purchase this particular variety $s$ at the same common price. The composite price of tradable goods is thus common to all islands and given by

$$
p_{M t}=\left(\int p_{X t}(s)^{1-\mu} d s\right)^{\frac{1}{1-\mu}},
$$

where $p_{X t}(s)$ denotes the price of a tradable variety produced on island $s$. The demand on island $s^{\prime}$ for a tradable variety produced on $s$ is therefore

$$
x_{M t}\left(s^{\prime}, s\right)=\left(\frac{p_{X t}(s)}{p_{M t}}\right)^{-\mu} x_{M t}\left(s^{\prime}\right),
$$

so that the world demand for tradable goods produced by an island $s$ is given by

$$
y_{X t}(s)=\int x_{M t}\left(s^{\prime}, s\right) d s^{\prime}=p_{X t}(s)^{-\mu} y_{W t},
$$

where $y_{W t}=p_{M t}^{\mu} \int x_{M t}\left(s^{\prime}\right) d s^{\prime}$.

Since any individual island is of measure zero, shocks to an individual island do not affect either the world aggregate price, $p_{M t}$, or demand, $y_{W t}$. Since we consider shocks to only a subset of islands that, taken together, are small in the world economy, world aggregate quantities and prices are constant. We normalize the constant world price of composite tradable goods, $p_{M t}$, to 1 so that the composite tradable is the numeraire.

Family's Problem. Consider the problem of a family on a given island $s$. Since from now on we focus on one island $s$, for simplicity we suppress the dependence on $s$. The preferences of a family are

$$
\sum_{t=0}^{\infty} \beta^{t} u\left(c_{t}\right)
$$

where the family's consumption $c_{t}=x_{t}+b_{t}$ is the sum of the amount of goods purchased, $x_{t}$, and home-produced, $b_{t}$. The budget constraint is

$$
p_{t} x_{t}+q a_{t+1}=y_{t}+d_{t}+b_{t}+a_{t},
$$

where $p_{t}$ is the price of composite goods on the island, $a_{t}$ are the family's assets, $y_{t}$ is the income of the family's workers in the form of wages, and $d_{t}$ are the profits from the firms the family owns on island $s$. The debt constraint on island $s$ is

$$
a_{t+1} \geq-\chi_{t}
$$

Note that the consumption problem of the family is almost identical to that in the one-good model. The one difference is that the shadow price of one unit of composite goods at date $t$ in units of date 0 composite goods is $Q_{t}=\beta^{t} u^{\prime}\left(c_{t}\right) / p_{t}$, where for simplicity we normalize $u^{\prime}\left(c_{0}\right) / p_{0}=1$. 
Technology. Nontradable and tradable goods are produced with locally produced intermediate goods. These intermediate goods are used by the nontradable and tradable sectors in different proportions. This setup effectively introduces costs of sectoral reallocations of workers because it implies a curved production possibility frontier between nontradable and tradable goods.

Specifically, this economy has two types of intermediate goods: type $\mathcal{N}$ and type $\mathcal{X}$ goods. The technology for producing nontradable goods disproportionately uses type $\mathcal{N}$ goods, whereas the technology for producing tradable goods disproportionately uses type $\mathcal{X}$ goods according to the production technologies

$$
y_{N t}=A\left(y_{N t}^{\mathcal{N}}\right)^{\nu}\left(y_{N t}^{\mathcal{X}}\right)^{1-\nu} \quad \text { and } \quad y_{X t}=A\left(y_{X t}^{\mathcal{N}}\right)^{1-\nu}\left(y_{X t}^{\mathcal{X}}\right)^{\nu}
$$

with $\nu \geq 1 / 2$. Here $y_{N}^{\mathcal{N}}$ and $y_{X}^{\mathcal{N}}$ denote the use of intermediate inputs of type $\mathcal{N}$ in the production of nontradable and tradable goods, whereas $y_{N}^{\mathcal{X}}$ and $y_{X}^{\mathcal{X}}$ denote the use of intermediate inputs of type $\mathcal{X}$ in the production of nontradable and tradable goods. Both nontradable goods producers and tradable goods producers are competitive and take as given the price of their goods, $p_{N t}$ and $p_{X t}$. The demands for intermediate inputs in the nontradable sector are given by

$$
y_{N t}^{\mathcal{N}}=\nu\left(\frac{p_{t}^{\mathcal{X}}}{p_{t}^{\mathcal{N}}}\right)^{1-\nu} y_{N t} \quad \text { and } \quad y_{N t}^{\mathcal{X}}=(1-\nu)\left(\frac{p_{t}^{\mathcal{N}}}{p_{t}^{\mathcal{X}}}\right)^{\nu} y_{N t},
$$

where $p_{t}^{\mathcal{X}}$ and $p_{t}^{\mathcal{N}}$ are the prices of the intermediate goods $\mathcal{N}$ and $\mathcal{X}$-here we have used the convenient normalization $A=\nu^{-\nu}(1-\nu)^{-(1-\nu)}$. Likewise, the demands for intermediate inputs in the tradable sector are

$$
y_{X t}^{\mathcal{N}}=(1-\nu)\left(\frac{p_{t}^{\mathcal{X}}}{p_{t}^{\mathcal{N}}}\right)^{\nu} y_{X t} \quad \text { and } \quad y_{X t}^{\mathcal{X}}=\nu\left(\frac{p_{t}^{\mathcal{N}}}{p_{t}^{\mathcal{X}}}\right)^{1-\nu} y_{X t}
$$

The zero profit conditions in the nontradable and tradable goods sectors imply

$$
p_{N t}=\left(p_{t}^{\mathcal{N}}\right)^{\nu}\left(p_{t}^{\mathcal{X}}\right)^{1-\nu} \quad \text { and } \quad p_{X t}=\left(p_{t}^{\mathcal{N}}\right)^{1-\nu}\left(p_{t}^{\mathcal{X}}\right)^{\nu}
$$

We assume that there are measures of consumers that can produce each of the two types of intermediate goods, denoted $i \in\{\mathcal{N}, \mathcal{X}\}$. We refer to these consumers as being in occupations $\mathcal{N}$ and $\mathcal{X}$. Consumers are hired by intermediate goods firms that produce these goods, which are then sold at competitive prices $p_{t}^{\mathcal{N}}$ and $p_{t}^{\mathcal{X}}$ to firms in the nontradable and tradable sectors. Of course, it is equivalent to think that the consumers in each occupation are assigned to the sector that purchases the goods they produce. Under this interpretation, we can think of consumers in occupation $\mathcal{X}$ as employed in sector $N$ and $X$ and consumers in occupation $\mathcal{N}$ as employed in sector $N$ and $X$. Furthermore, sector $N$ employs consumers in occupation 
$\mathcal{N}$ relatively intensively, whereas sector $X$ employs consumers in occupation $\mathcal{X}$ relatively intensively.

Our setup captures in a simple way the idea that switching sectors is relatively easy whereas switching occupations is difficult. Here any individual consumer faces no cost of switching sectors, but if a positive measure of consumers moves from one sector to another, it reduces those workers' marginal revenue products and, thus, their wages. This reduction in marginal revenue products acts like a switching cost in the aggregate.

Labor Market. Firms that produce intermediate good $i \in\{\mathcal{N}, \mathcal{X}\}$ post vacancies for consumers in occupation $i$ with general human capital $z$, who produce intermediate good $i$ when matched. We assume that consumers cannot switch occupations, so the measure of workers in each occupation is fixed. The values of consumers in occupation $i$ with general human capital $z$ and firm-specific human capital $h$ are similar to those in our one-good model and are given by

$$
\begin{aligned}
W_{t}^{i}(z, h)= & Q_{t} \omega_{t}^{i}(z, h)+\phi(1-\sigma) \int \psi_{t+1}^{i}\left(z^{\prime}, h^{\prime}\right) W_{t+1}^{i}\left(z^{\prime}, h^{\prime}\right) d F_{e}\left(z^{\prime} \mid z\right) \\
& +\phi \int\left\{(1-\sigma)\left[1-\psi_{t+1}^{i}\left(z^{\prime}, h^{\prime}\right)\right]+\sigma\right\} U_{t+1}^{i}\left(z^{\prime}\right) d F_{e}\left(z^{\prime} \mid z\right)
\end{aligned}
$$

and

$$
\begin{aligned}
U_{t}^{i}(z)= & Q_{t} b(z)+\phi \lambda_{w t}^{i}(z) \int \psi_{t+1}^{i}\left(z^{\prime}, 1\right) W_{t+1}^{i}\left(z^{\prime}, 1\right) d F_{u}\left(z^{\prime} \mid z\right) \\
& +\phi \int\left\{\lambda_{w t}^{i}(z)\left[1-\psi_{t+1}^{i}\left(z^{\prime}, 1\right)\right]+1-\lambda_{w t}^{i}(z)\right\} U_{t+1}^{i}\left(z^{\prime}\right) d F_{u}\left(z^{\prime} \mid z\right)
\end{aligned}
$$

where $\omega_{t}^{i}(z, h)$ is the wage received by a consumer in occupation $i$ as a function of human capital, $\psi_{t}^{i}(z, h)$ is an indicator variable for whether a firm continues a match or destroys it, and $\lambda_{w t}^{i}(z)$ is the consumer's job-finding probability.

The value of a firm producing intermediate good $i$ matched with a worker in occupation $i$ with productivity $(z, h)$ is

$$
J_{t}^{i}(z, h)=Q_{t}\left[p_{t}^{i} z h-\omega_{t}^{i}(z, h)\right]+(1-\sigma) \phi \int \max \left[J_{t+1}^{i}\left(z^{\prime}, h^{\prime}\right), 0\right] d F_{e}\left(z^{\prime} \mid z\right) .
$$

That is, at date $t$ a worker in occupation $i$ with human capital $(z, h)$ matched with a firm in intermediate good sector $i$ produces $z h$ units of good $i$, which sell for $p_{t}^{i} z h$, and the firm pays the worker $\omega_{t}^{i}(z, h)$. The cost of posting a vacancy is $\kappa$ units of the composite tradable good. The free-entry condition in sector $i$ is analogous to (11).

The matching technology for firms producing intermediate good $i$ is the same as in the one-good model. The matches of firms that produce intermediate good $i$ with workers with 
general human capital $z$ are given by

$$
m_{t}^{i}(z)=u_{t}^{i}(z) v_{t}^{i}(z) /\left[u_{t}^{i}(z)^{\eta}+v_{t}^{i}(z)^{\eta}\right]^{\frac{1}{\eta}}
$$

where $u_{t}^{i}(z)$ is the measure of nonemployed workers and $v_{t}^{i}(z)$ is the measure of vacancies directed at such workers. The associated worker job-finding rate $\lambda_{w t}^{i}(z)$ and firm matching rate $\lambda_{f t}^{i}(z)$ then follow as before. The determination of wages by Nash bargaining is exactly analogous to that in the one-good model.

Consider next the market clearing conditions. Market clearing for the two types of intermediate goods requires

$$
\int_{z, h} z h d e_{t}^{i}(z, h)=y_{N t}^{i}+y_{X t}^{i} \text { for } i \in\{\mathcal{N}, \mathcal{X}\}
$$

The left side of this equation is the total amount of intermediate goods of type $i$ produced by the measure of employed workers, $e_{t}^{i}(z, h)$, and the right side is the total amount of these intermediate goods used by firms in the nontradable and tradable sectors.

Market clearing for nontradable goods can be written as $x_{N t}=y_{N t}$. Market clearing for tradable goods requires that the demand for these goods in (23) equals the supply of these goods in (24).

\subsection{The Workings of the Richer Model}

Consider how employment responds to a debt tightening in this version of the model. In contrast to the one-good model, here consumers can reallocate across sectors. The cost of this reallocation is governed by the curvature of the production possibility frontier between nontradable and tradable goods: the more curved this frontier (the higher is $\nu$ ), the higher the cost of reallocation. Mechanically, as $\nu$ increases, a given flow of consumers into a sector leads to a greater fall in the marginal product and thus wages in that sector.

In this environment, a credit tightening has two effects on employment. The first, the investment effect, is similar to that in the one-good model: the cost of posting vacancies increases by more than the surplus from a match, leading firms in both sectors to post fewer vacancies and, hence, to a drop in overall employment.

The second, the relative demand effect, is due to the reduction in the demand for nontradable goods produced on the island and thus their relative price. This drop in prices amplifies the drop in employment in the nontradable sector relative to that in the tradable sector. When the cost of sectoral reallocation is small, a large flow of labor from the nontradable to the tradable sector ensues. This reallocation can be so large that even though overall employment declines, employment in the tradable sector increases. In contrast, when the 
cost of sectoral reallocation is large, there is little flow of labor from the nontradable to the tradable sector so that employment falls in both sectors.

Thus, in response to a credit tightening, nontradable employment falls unambiguously, because of both the investment effect and the reallocation effect. The response of tradable employment is ambiguous. If sectoral reallocation is costly (high $\nu$ ), then tradable employment falls because the investment effect dominates the reallocation effect. If, in contrast, sectoral reallocation is not too costly (low $\nu$ ), then tradable employment increases because the reallocation effect more than offsets the investment effect.

To see these effects, consider first the extreme case in which the two sectors use the two occupations equally intensively, that is, an economy with $\nu=1 / 2$, in which the costs of sectoral reallocation are relatively low and the remaining parameter values are equal to those in the quantitative model discussed later. Figure 12 shows the response to a credit tightening that generates a 5\% drop in consumption. As the figure shows, in this case tradable employment expands because of the inflow of workers from the nontradable sector.

Consider the second extreme case in which consumers cannot switch sectors, that is, an economy with $\nu=1$. As Figure 13 shows, in this case a similar credit tightening leads both tradable and nontradable employment to fall. The drop in tradable employment is somewhat smaller since it is driven solely by the investment effect. Because the price of nontradable output falls more than tradable output, firms find it even less attractive to post vacancies in that sector.

For $\nu$ in between these two extremes, employment in both occupations falls, employment in the nontradable sector falls and employment in the tradable sector can either rise or fall depending on $\nu$. As we discuss later, we discipline our choice of $\nu$ by the patterns of tradable employment in the Great Recession.

\subsection{Comparison with Cross-Sectional Data}

We begin by discussing how we set parameters in this new version of the model. There are five new parameters, in addition to those in the one-good model. We choose the parameter $\tau$ so that the share of spending on nontradable goods is $2 / 3$ and the trade elasticity $\mu_{X}$ is 4. Both of these numbers are fairly standard in the trade literature. We choose the fraction of consumers in the two occupations to ensure that in the steady state, wages in the two occupations are the same for a given level of human capital. Given this choice, the steadystate implications of this richer model are identical to those of the one-good model reported in panel A of Table 1, and so we choose the rest of the parameters as we did before in panel B of Table 1.

As discussed earlier, one key parameter in this richer version of the model is the param- 
eter $\nu$ governing the curvature of the production possibility frontier between tradable and nontradable goods. This parameter allows us to capture, in a parsimonious yet flexible way, the cost of reallocating workers across the two sectors. We choose this parameter by requiring our model to reproduce the Mian and Sufi (2014) observation that declines in consumption across states were essentially unrelated to changes in tradable employment. Specifically, we choose $\nu$ so as to generate an elasticity of tradable employment to consumption of -0.03 . The resulting share is $\nu=0.87$.

A second key parameter is $\mu$, the elasticity of substitution between tradable and nontradable goods. The lower $\mu$ is, the more the relative price of nontradable goods falls following a credit tightening and, thus, the more wages fall. We choose this parameter to reproduce the observation of Beraja, Hurst, and Ospina (2016) that in the cross section of U.S. states, wages are moderately flexible. Specifically, we choose $\mu$ so as to generate an elasticity of wages to employment of 0.78 . The resulting elasticity of substitution is $\mu=2.5$.

We next describe the experiments we conduct. For each state, we choose a sequence of shocks to the debt limit so that the model exactly reproduces the predicted consumption series for each state in the data. Each of these shocks is unanticipated. As in our one-good model, the path for shocks is such that agents believe that consumption will revert to its steady state at a rate of $10 \%$ per quarter. Given these paths for shocks, we calculate the evolution of state-level variables. We then calculate the summary statistics in our model and compare these with the corresponding statistics in the data summarized in Table 4.

As discussed, we have chosen the parameters $\nu$ and $\mu$ so that the model reproduces the observed elasticities of nontradable employment to consumption and of wages to employment. We now evaluate the extent to which the model can account for how overall employment and nontradable employment fell as consumption fell during the Great Recession.

Recall that in the data, a fall in consumption across states of $10 \%$ is associated with a fall in nontradable employment of $5.5 \%$ and a drop in employment of $3.8 \%$. As Table 4 shows, our model implies that such a fall in consumption is associated with a fall in nontradable employment of $5.7 \%$ and a fall in overall employment of $3.3 \%$. Thus, our model successfully accounts for the comovements of consumption and both nontradable employment and overall employment.

Table 5 shows how these elasticities change as we vary the cost of reallocating workers from one extreme case with low costs of reallocating workers $(\nu=0.5)$ to the other extreme case with prohibitively high costs of reallocating workers $(\nu=1)$. When reallocation costs are low, the relative demand effect dominates the investment effect, leading to a counterfactually sharp decline in nontradable employment and a sharp increase in tradable employment. The model's implication for the comovement of employment and wages is also grossly at odds 
with the data: wages comove too little with employment compared with the data. When reallocation costs are high, the investment effect dominates the relative demand effect, leading, counterfactually, to similarly sized declines in nontradable and tradable employment following a credit tightening.

Table 5 also shows how these elasticities change as we vary the elasticity of substitution between tradable and nontradable goods from a relatively low elasticity of $\mu=1$ to a relatively high elasticity of $\mu=5$. When this elasticity is low, nontradable goods prices fall a lot, leading to a counterfactually large wage drop, whereas when this elasticity is high, nontradable goods prices fall little, leading to a counterfactually small wage drop.

Table 6 shows the effects of eliminating the growth in human capital accumulation. In our baseline model, we chose the values of $\nu$ and $\mu$ so that the model reproduces the features that wages are moderately flexible and that tradable employment does not comove with consumption in the cross section. Table 6 shows that, regardless of the values of these parameters, the model without human capital is unable to come anywhere close to reproducing these features. Moreover, consistent with our results from the one-good model, for all such values, the overall employment responses are much smaller than those in both the baseline model and the data.

\section{Conclusion}

We have explored the interplay between credit and labor market frictions in accounting for the regional comovements between consumption, employment, and wages during the Great Recession in the United States. The key idea we developed is that in a search and matching model, hiring a worker is an investment activity and is thus affected by credit frictions.

In the standard DMP model, the returns to posting vacancies are so short-lived, though, that the model is essentially static so that vacancies are not sensitive to a tightening of credit. In contrast, once we introduce on-the-job human capital accumulation large enough to allow the model to reproduce the evidence on wage growth over the life cycle and on the job, the returns to posting vacancies are much longer-lived and thus sensitive to a tightening of credit. We show that the model accounts well for the cross-regional patterns of consumption, employment, and wages observed during the Great Recession.

\section{References}

Altonji, Joseph G., and Robert A. Shakotko. 1987. Do wages rise with job seniority? Review of Economic Studies, 54 (3), 437-459. 
Andolfatto, David. 1996. Business cycles and labor-market search. American Economic Review, 86 (1), 112-132.

Beraja, Martin, Erik Hurst, and Juan Ospina. 2016. The aggregate implications of regional business cycles. National Bureau of Economic Research Working Paper 21956.

Bernanke, Ben, and Mark Gertler. 1989. Agency costs, net worth, and business fluctuations. American Economic Review, 79 (1), 14-31.

Bernanke, Ben S., Mark Gertler, and Simon Gilchrist. 1999. The financial accelerator in a quantitative business cycle framework. In Handbook of Macroeconomics, vol. 1C, ed. John B. Taylor and Michael Woodford, 1341-1393. Amsterdam: North-Holland.

Buchinsky, Moshe, Denis Fougère, Francis Kramarz, and Rusty Tchernis. 2010. Interfirm mobility, wages and the returns to seniority and experience in the United States. Review of Economic Studies, 77 (3), 972-1001.

Chari, V.V., Patrick J. Kehoe, and Ellen R. McGrattan. 2005. Sudden stops and output drops. American Economic Review, 95 (2), 381-387.

Charles, Kerwin Kofi, Erik Hurst, and Matthew J. Notowidigdo. 2015. Housing booms and busts, labor market opportunities, and college attendance. National Bureau of Economic Research Working Paper 21587.

Davis, Morris A., and Stijn Van Nieuwerburgh. 2014. Housing, finance and the macroeconomy. National Bureau of Economic Research Working Paper 20287.

Den Haan, Wouter J., Garey Ramey, and Joel Watson. 2000. Job destruction and the experiences of displaced workers. In Carnegie-Rochester Conference Series on Public Policy, vol. 52, ed. Bennett T. McCallum and Charles I. Plosser, 87-128. Amsterdam: NorthHolland.

Eggertsson, Gauti B., and Paul Krugman. 2012. Debt, deleveraging, and the liquidity trap: A Fisher-Minsky-Koo approach. Quarterly Journal of Economics, 127 (3), 1469-1513.

Eisfeldt, Andrea L., and Adriano A. Rampini. 2007. New or used? Investment with credit constraints. Journal of Monetary Economics, 54 (8), 2656-2681.

Elsby, Michael W.L., and Matthew D. Shapiro. 2012. Why does trend growth affect equilibrium employment? A new explanation of an old puzzle. American Economic Review, 102 (4), 1378-1413.

Floden, Martin, and Jesper Lindé. 2001. Idiosyncratic risk in the United States and Sweden: Is there a role for government insurance? Review of Economic Dynamics, 4 (2), 406-437.

Gertler, Mark, and Peter Karadi. 2011. A model of unconventional monetary policy. Journal of Monetary Economics, 58 (1), 17-34.

Gertler, Mark, and Nobuhiro Kiyotaki. 2010. Financial intermediation and credit policy 
in business cycle analysis. In Handbook of Monetary Economics, vol. 3, ed. Benjamin M. Friedman and Michael Woodford, 547-599. Amsterdam: North-Holland.

Gilchrist, Simon, and Egon Zakrajšek. 2012. Credit spreads and business cycle fluctuations. American Economic Review, 102 (4), 1692-1720.

Giroud, Xavier, and Holger M. Mueller. Forthcoming. Firm leverage and unemployment during the Great Recession. Quarterly Journal of Economics.

Guerrieri, Veronica, and Guido Lorenzoni. 2015. Credit crises, precautionary savings, and the liquidity trap. Chicago Booth mimeo.

Guvenen, Fatih. 2006. Reconciling conflicting evidence on the elasticity of intertemporal substitution: A macroeconomic perspective. Journal of Monetary Economics, 53 (7), 14511472.

Hagedorn, Marcus, and Iourii Manovskii. 2008. The cyclical behavior of equilibrium unemployment and vacancies revisited. American Economic Review, 98 (4), 1692-1706.

Hall, Robert E. 2014. High discounts and high unemployment. National Bureau of Economic Research Working Paper 19871.

Hall, Robert E., and Paul R. Milgrom. 2008. The limited influence of unemployment on the wage bargain. American Economic Review, 98 (4), 1653-1674.

Head, Allen, and Huw Lloyd-Ellis. 2012. Housing liquidity, mobility, and the labor market. Review of Economic Studies, 79 (4), 1559-1589.

Itskhoki, Oleg, and Elhanan Helpman. 2015. Trade liberalization and labor market dynamics with heterogeneous firms. Princeton University mimeo.

Kaplan, Greg, and Giovanni L. Violante. 2014. A model of the consumption response to fiscal stimulus payments. Econometrica, 82 (4), 1199-1239.

Kiyotaki, Nobuhiro, and John Moore. 1997. Credit cycles. Journal of Political Economy, 105 (2), 211-248.

Krusell, Per, Toshihiko Mukoyama, and Ayşegül Şahin. 2010. Labour-market matching with precautionary savings and aggregate fluctuations. Review of Economic Studies, 77 (4), 1477-1507.

Krusell, Per, Toshihiko Mukoyama, Richard Rogerson, and Ayşegül Şahin. 2011. A three state model of worker flows in general equilibrium. Journal of Economic Theory, 146 (3), 1107-1133.

Ljungqvist, Lars, and Thomas J. Sargent. 2008. Two questions about European unemployment. Econometrica, 76 (1), 1-29.

1998. The European unemployment dilemma. Journal of Political Economy, $106(3), 514-550$.

McCall, John, J. 1970. Economics of information and job search. Quarterly Journal of 
Economics, 84 (1), 113-126.

Mendoza, E. 2010. Sudden stops, financial crises, and leverage. American Economic Review, 100 (5), 1941-1946.

Merz, Monika. 1995. Search in the labor market and the real business cycle. Journal of Monetary Economics, 36 (2), 269-300.

Mian, Atif, and Amir Sufi. 2014. What explains the 2007-2009 drop in employment? Econometrica, 82 (6), 2197-2223.

2011. House prices, home equity-based borrowing, and the U.S. household leverage crisis. American Economic Review, 101 (5), 2132-2156.

Mian, Atif, Kamalesh Rao, and Amir Sufi. 2013. Household balance sheets, consumption, and the economic slump. Quarterly Journal of Economics, 128 (4), 1687-1726.

Midrigan, Virgiliu, and Thomas Philippon. 2016. Household leverage and the recession. NYU mimeo.

Ohanian, Lee. 2010. The economic crisis from a neoclassical perspective. Journal of Economic Perspectives, 24 (4), 45-66.

Pinheiro, Roberto, and Ludo Visschers. 2015. Unemployment risk and wage differentials. Journal of Economic Theory, 157 (3), 397-424.

Pissarides, Christopher A. 1992. Loss of skill during unemployment and the persistence of employment shocks. Quarterly Journal of Economics, 107 (4), 1371-1391.

Rubinstein, Yona, and Yoram Weiss. 2006. Post schooling wage growth: Investment, search and learning. In Handbook of the Economics of Education, vol. 1, ed. Eric A. Hanushek and Finis Welch, 1-67. Amsterdam: North Holland.

Shimer, R. 2012. Reassessing the ins and outs of unemployment. Review of Economic Dynamics, 15 (2), 127-148.

2005. The cyclical behavior of equilibrium unemployment and vacancies. American Economic Review, 95 (1), 25-49.

Song, Jae, David J. Price, Fatih Guvenen, Nicholas Bloom, and Till von Wachter. Forthcoming. Firming up inequality. In Firms and the Distribution of Income: The Roles of Productivity and Luck. National Bureau of Economic Research.

Topel, Robert. 1999. Labor markets and economic growth. In Handbook of Labor Economics, vol 3C, ed. Orley C. Ashenfelter and David Card, 2943-2984. Amsterdam: NorthHolland.

1991. Specific capital, mobility, and wages: Wages rise with job seniority. Journal of Political Economy, 99 (1), 145-176. 


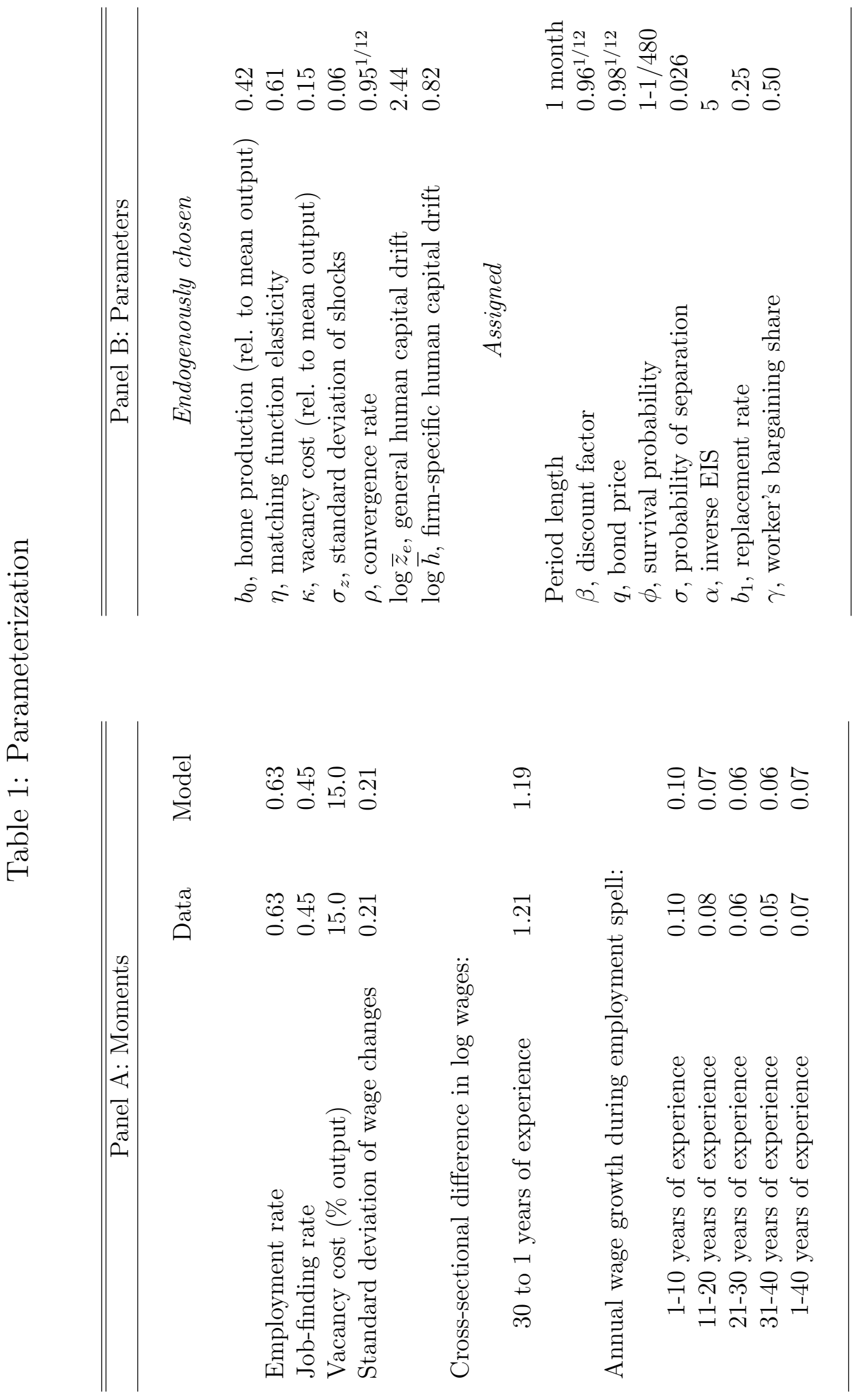


Table 2: Additional Model Implications

Fraction both nonemployed and with positive match probability $\quad 0.04$

$\begin{array}{ll}\text { Mean home production to mean wage } & 0.48\end{array}$

$\begin{array}{ll}\text { Endogenous separations, \% } & 0.02\end{array}$

$\begin{array}{ll}\text { Std. dev. log wages } & 0.82\end{array}$

Profit share of revenue $\quad 0.06$

$\begin{array}{ll}\text { Mean wage drop after unemployment spell } & 0.05\end{array}$

Table 3A: Moments Targeted in Robustness Checks*

\begin{tabular}{|c|c|c|c|c|}
\hline & \multicolumn{2}{|c|}{ Altonji-Shakotko } & \multicolumn{2}{|c|}{ Topel } \\
\hline & Data & Model & Data & Model \\
\hline Employment rate & 0.63 & 0.63 & 0.63 & 0.63 \\
\hline Job-finding rate & 0.45 & 0.44 & 0.45 & 0.45 \\
\hline Vacancy cost (\% output) & 0.15 & 0.15 & 0.15 & 0.15 \\
\hline Std. dev. of wage changes & 0.21 & 0.21 & 0.21 & 0.21 \\
\hline Cross-sectional $\Delta \log w$ (30 to 1 years) & 0.80 & 0.78 & 0.80 & 0.81 \\
\hline On-the-job wage growth (1-10 years) & 0.05 & 0.05 & 0.08 & 0.08 \\
\hline On-the-job wage growth (11-20 years) & 0.04 & 0.04 & 0.05 & 0.06 \\
\hline On-the-job wage growth (21-30 years) & 0.03 & 0.03 & 0.04 & 0.05 \\
\hline On-the-job wage growth (31-40 years) & 0.02 & 0.02 & 0.04 & 0.04 \\
\hline On-the-job wage growth (1-40 years) & 0.03 & 0.03 & 0.05 & 0.05 \\
\hline
\end{tabular}

*Both calibrations use cross-sectional wage growth from Rubinstein and Weiss (2006).

Table 3B: Parameters Used in Robustness Checks

\begin{tabular}{lccc}
\hline \hline & Baseline & Altonji-Shakotko & Topel \\
\hline & & & \\
$b_{0}$, home production (rel. to mean output) & 0.42 & 0.39 & 0.51 \\
$\eta$, matching function elasticity & 0.61 & 0.77 & 0.72 \\
$\kappa$, vacancy cost (rel. to mean output) & 0.15 & 0.15 & 0.15 \\
$\sigma_{z}$, std. dev. of shocks & 0.06 & 0.06 & 0.06 \\
$\rho$, convergence rate & $0.95^{1 / 12}$ & $0.96^{1 / 12}$ & $0.93^{1 / 12}$ \\
$\log \bar{z}_{e}$, general human capital drift & 2.44 & 1.68 & 1.56 \\
$\log \bar{h}$, firm-specific human capital drift & 0.82 & 0.00 & 0.57 \\
& & & \\
\hline
\end{tabular}


Table 4: Cross-State Elasticities

\begin{tabular}{lcc}
\hline \hline & Data & Baseline Model \\
\hline Elasticity $\Delta e$ vs. $\Delta c$ & 0.38 & 0.33 \\
Elasticity $\Delta e_{N}$ vs. $\Delta c$ & 0.55 & 0.57 \\
Elasticity $\Delta e_{T}$ vs. $\Delta c$ & -0.03 & -0.03 \\
Elasticity $\Delta w$ vs. $\Delta e$ & 0.78 & 0.78 \\
\hline
\end{tabular}

Note: $\Delta e, \Delta e_{N T}$, and $\Delta e_{T}$ denote changes in overall, nontradable, and tradable employment; $\Delta c$ denotes changes in predicted consumption; $\Delta w$ denotes changes in wages.

Table 5: Alternative Parameterizations

\begin{tabular}{lccccc}
\hline \hline & Baseline & \multicolumn{2}{c}{ Varying $\nu$} & \multicolumn{2}{c}{ Varying $\mu$} \\
& Model & $\nu=0.5$ & $\nu=1$ & $\mu=1$ & $\mu=5$ \\
\hline Elasticity $\Delta e$ vs. $\Delta c$ & 0.33 & 0.49 & 0.27 & 0.25 & 0.40 \\
Elasticity $\Delta e_{N}$ vs. $\Delta c$ & 0.57 & 1.42 & 0.30 & 0.57 & 0.58 \\
Elasticity $\Delta e_{T}$ vs. $\Delta c$ & -0.03 & -0.85 & 0.23 & -0.21 & 0.13 \\
Elasticity $\Delta w$ vs. $\Delta e$ & 0.78 & 0.03 & 1.21 & 1.70 & 0.22 \\
\hline
\end{tabular}

Table 6: Model without Human Capital Accumulation

\begin{tabular}{lccccc}
\hline \hline & $\nu=0.87$ & \multicolumn{2}{c}{ Varying $\nu$} & \multicolumn{2}{c}{ Varying $\mu$} \\
& $\mu=2.5$ & $\nu=0.5$ & $\nu=1$ & $\mu=1$ & $\mu=5$ \\
\hline Elasticity $\Delta e$ vs. $\Delta c$ & 0.07 & 0.14 & 0.05 & 0.08 & 0.07 \\
Elasticity $\Delta e_{N}$ vs. $\Delta c$ & 0.41 & 0.90 & 0.22 & 0.51 & 0.31 \\
Elasticity $\Delta e_{T}$ vs. $\Delta c$ & -0.47 & -1.07 & -0.23 & -0.61 & -0.33 \\
Elasticity $\Delta w$ vs. $\Delta e$ & 5.72 & 2.07 & 9.89 & 6.71 & 4.57 \\
\hline
\end{tabular}


Figure 1: Steady-State Measures and Matching Rates

A. Measure Employed

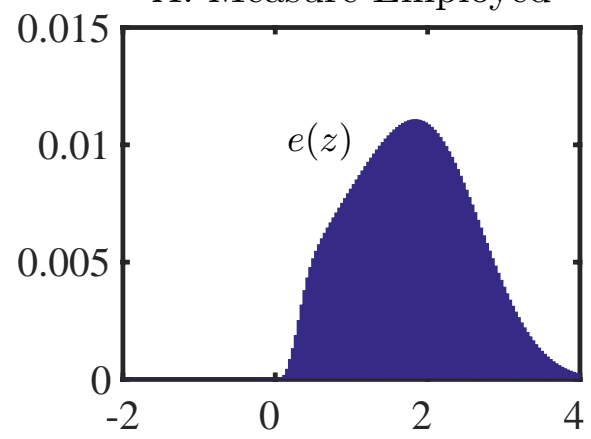

C. Firm Matching Rate

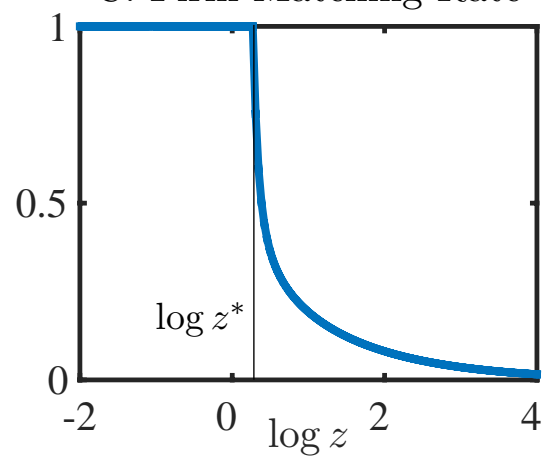

B. Measure Nonemployed

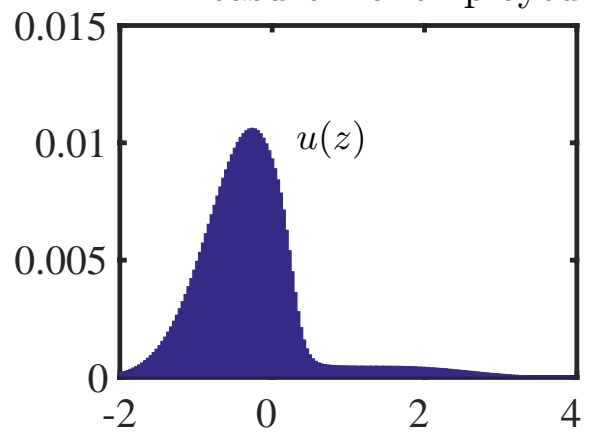

D. Worker Matching Rate

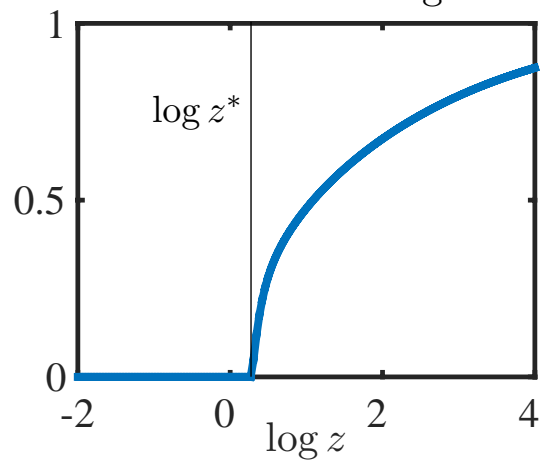

Figure 2: Example of Individual Wage Path

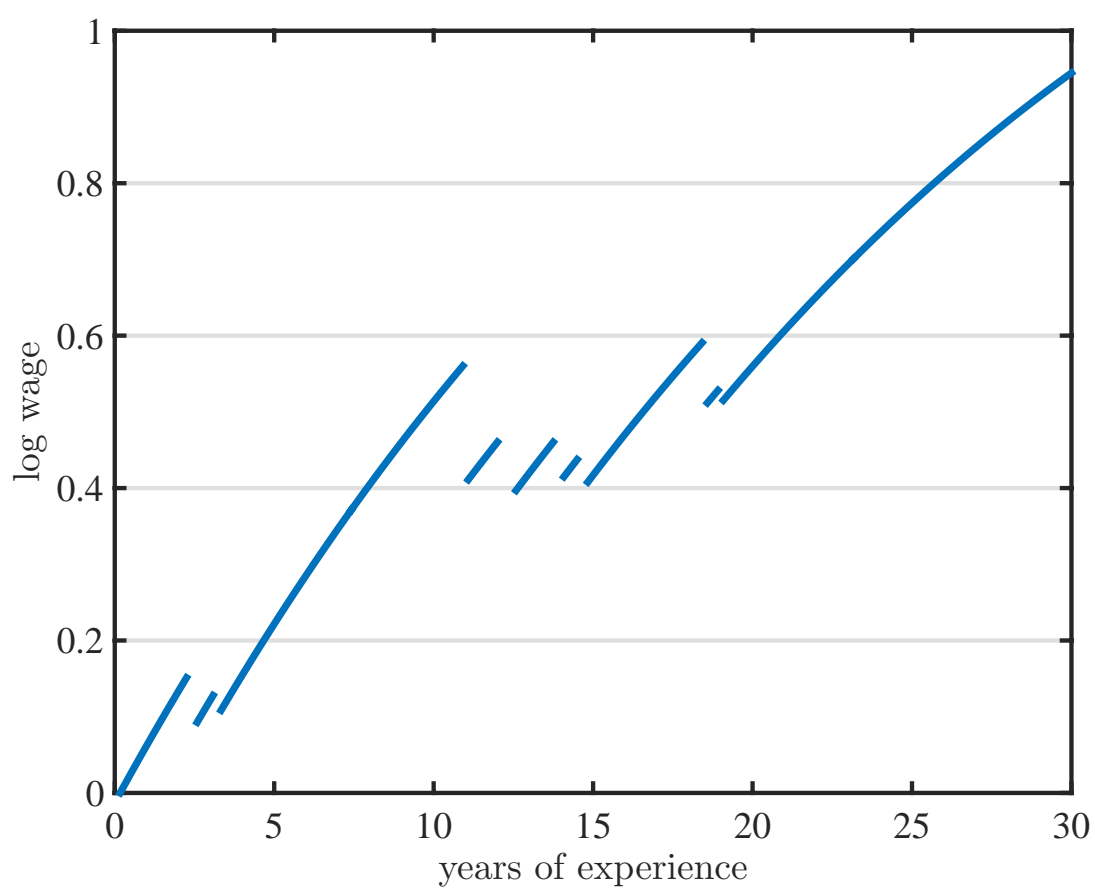


Figure 3: Employment Response to a Credit Tightening

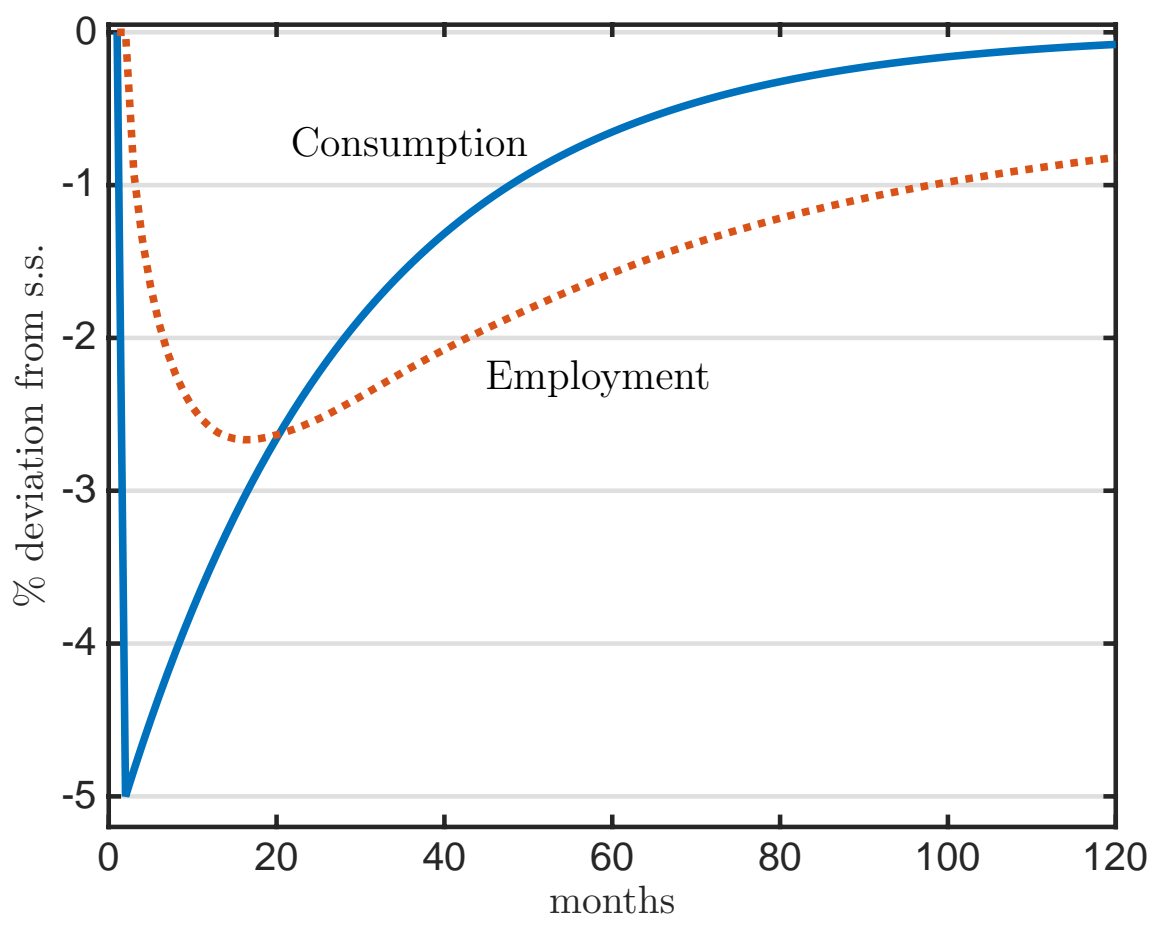

Figure 4: Shimer Decomposition of Employment

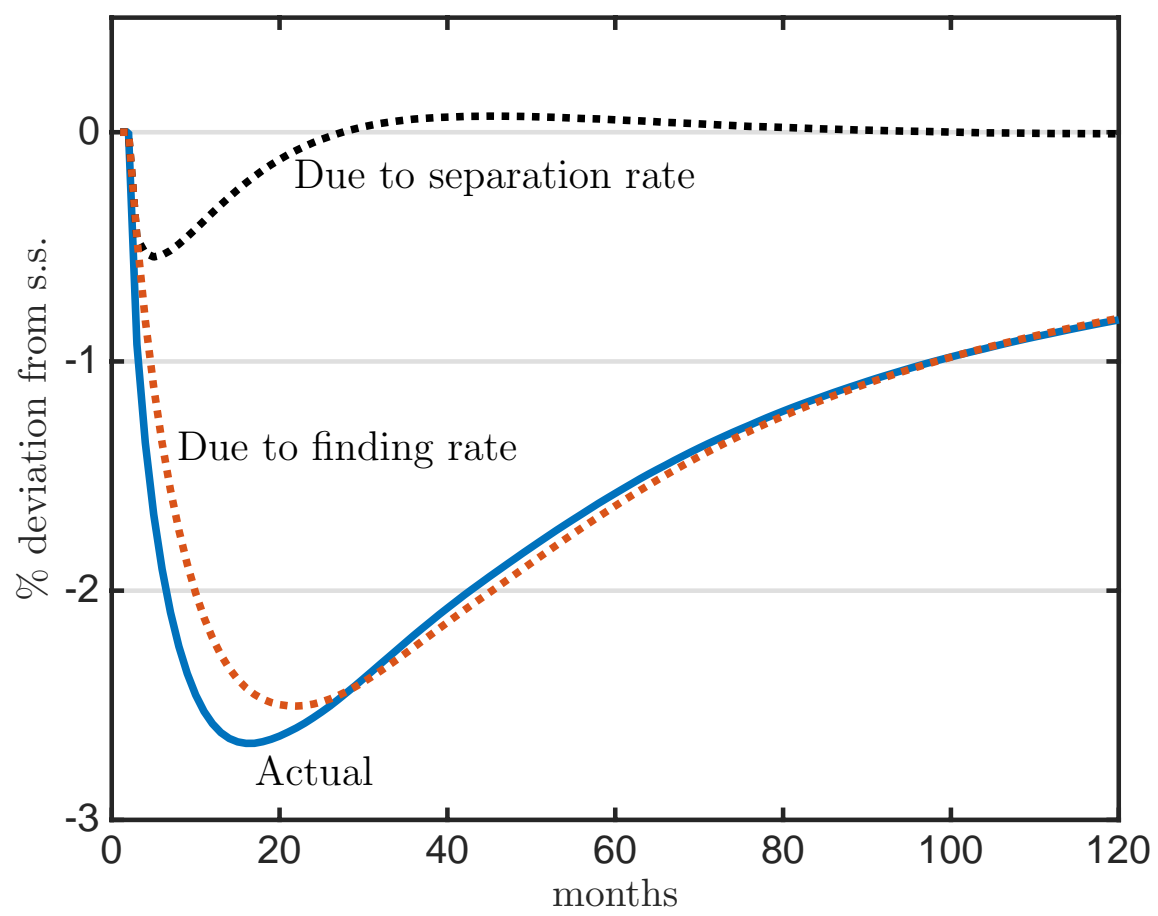


Figure 5: General Human Capital of Median Active Nonemployed Consumer

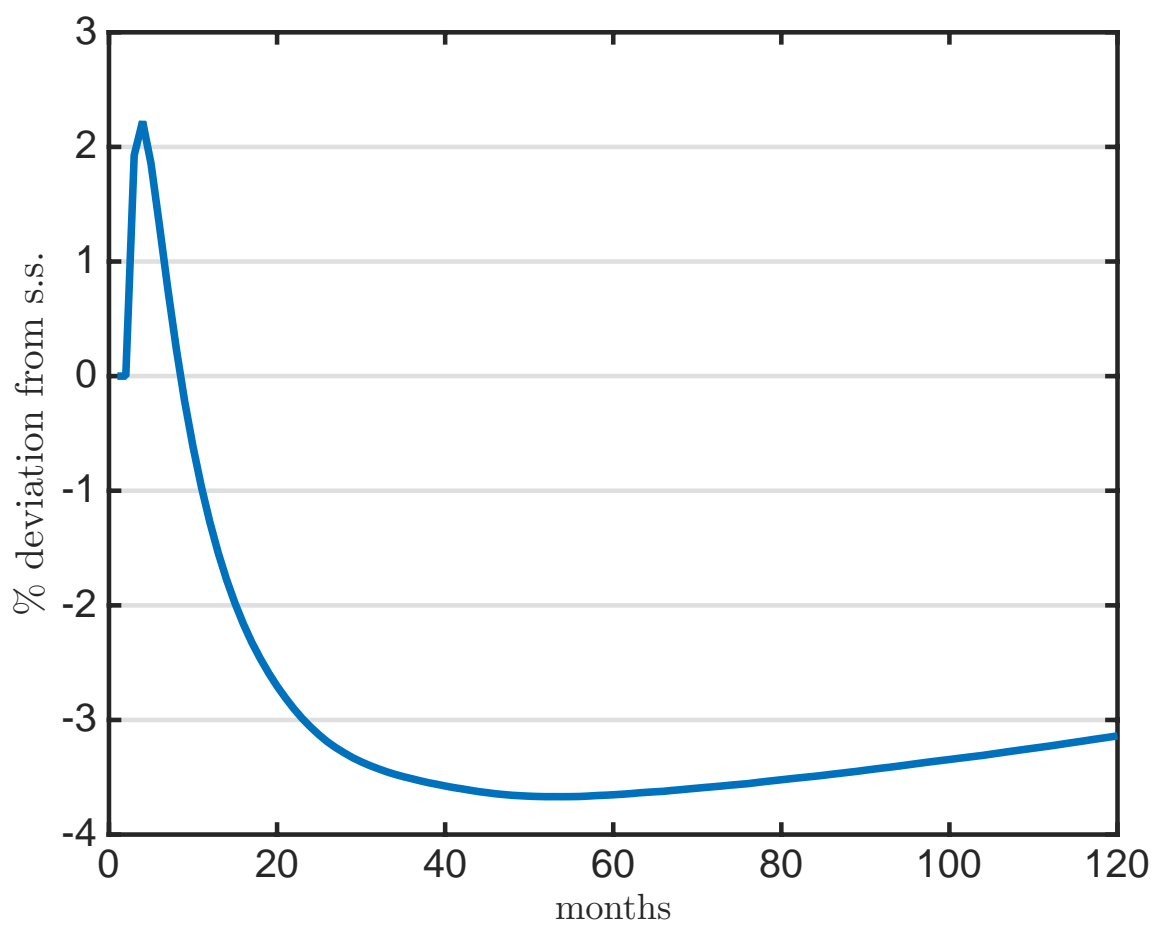

Figure 6: Employment Response without Human Capital Accumulation

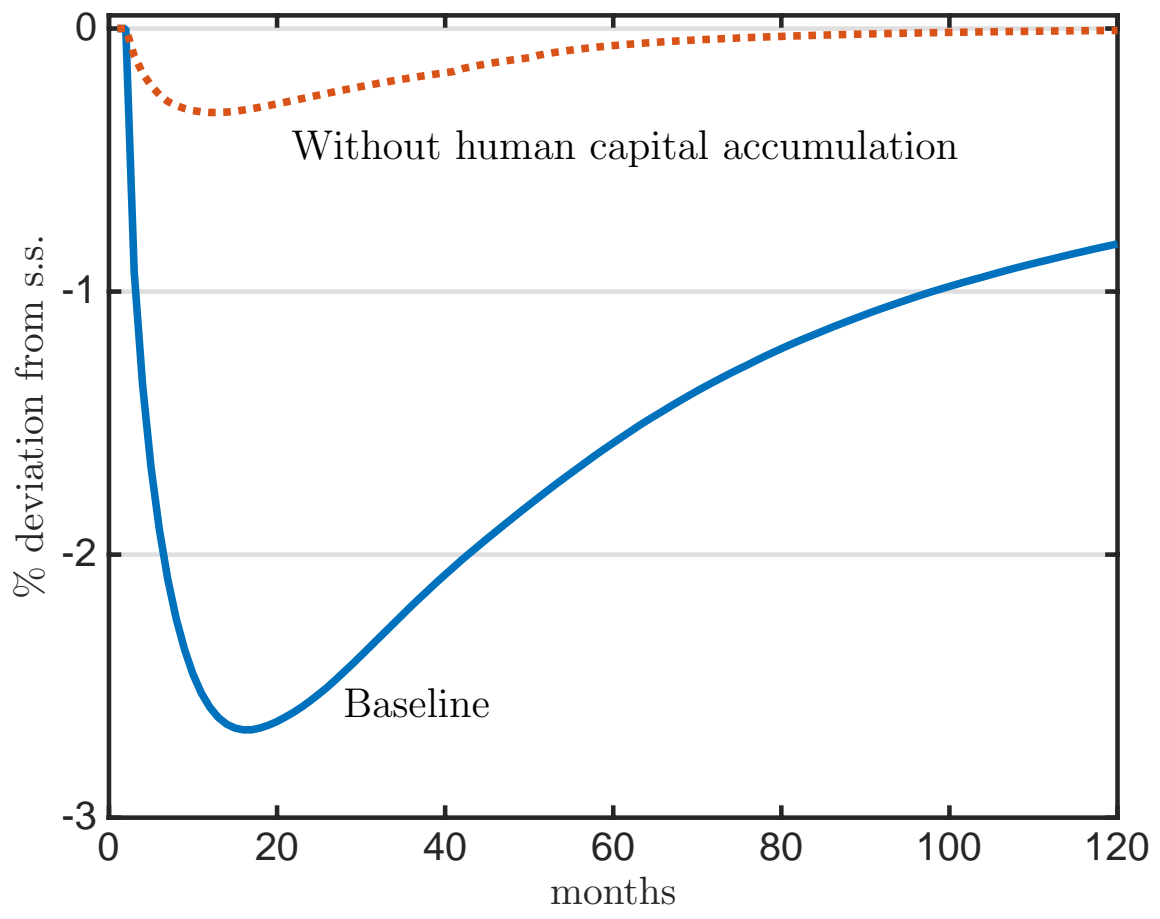


Figure 7: Employment Response with Only Firm-Side Credit Frictions

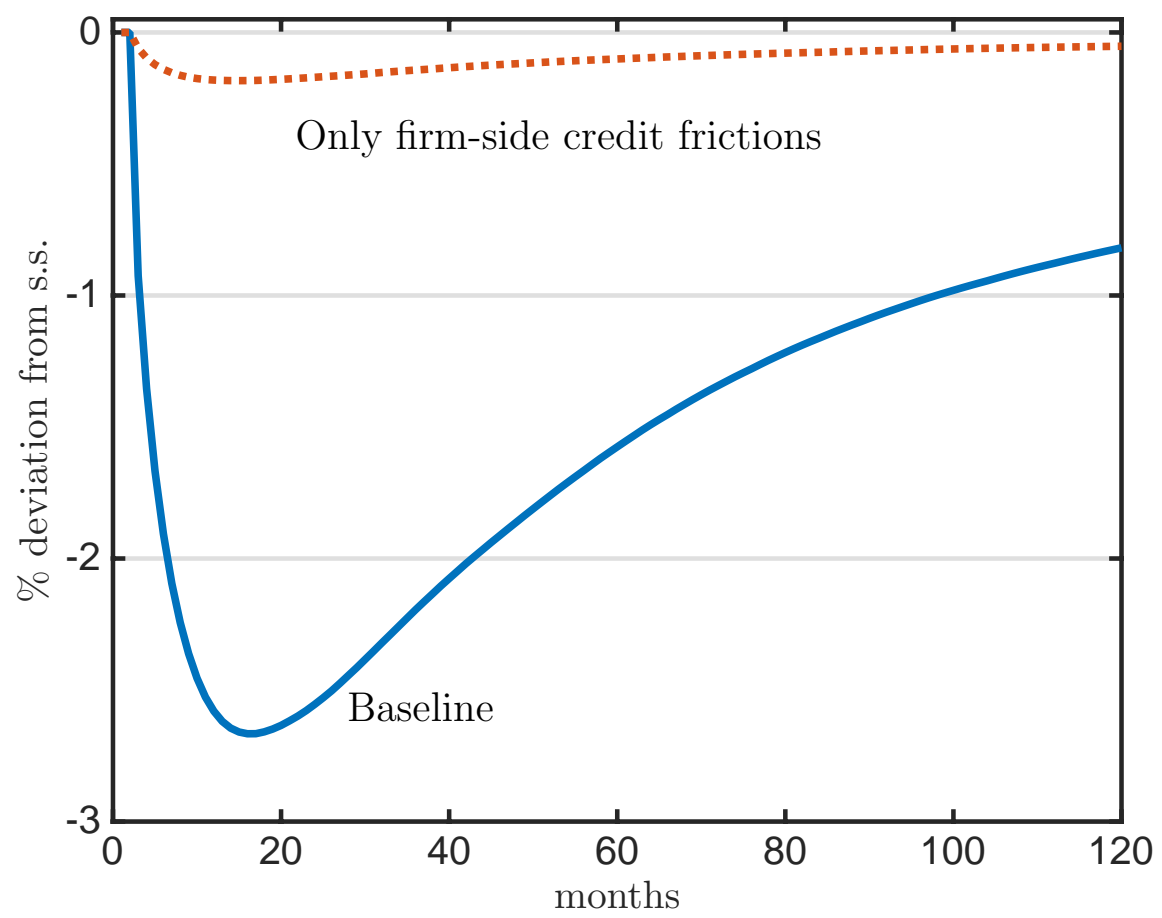

Figure 8: Employment Responses under Alternative Parameterizations

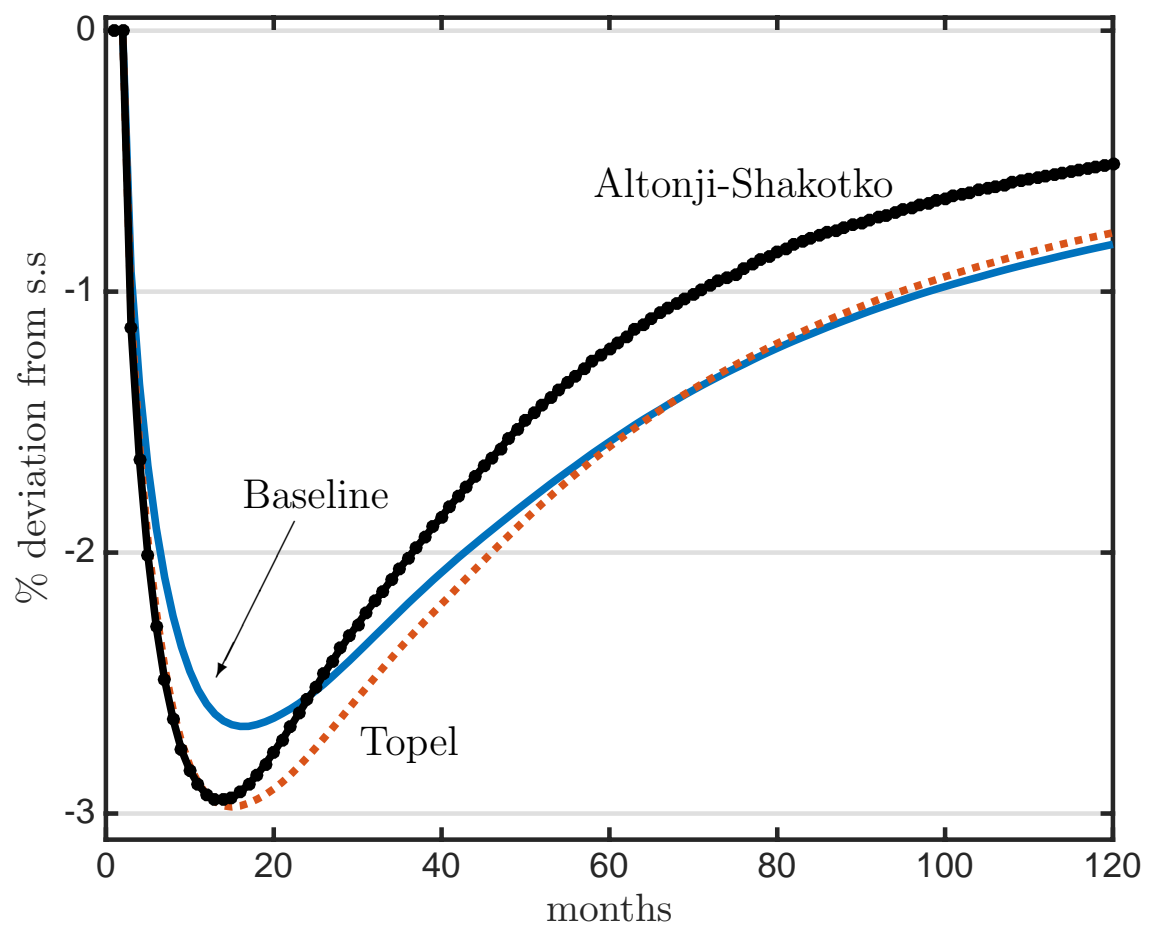




\section{Figure 9: Robustness Analysis}

A. On-the-Job Wage Growth

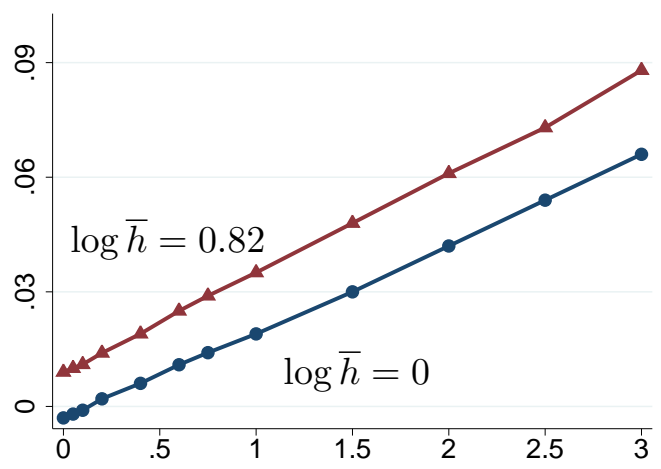

C. Maximal Employment Drop

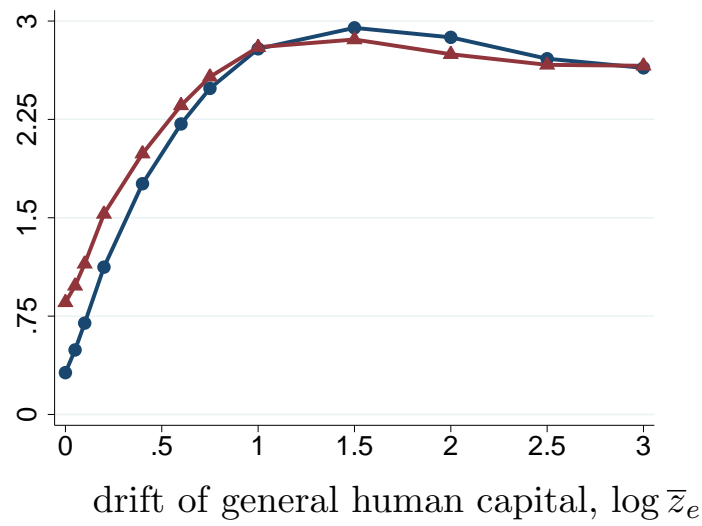

B. Cross-Sectional WageDifference(1-30 Years)

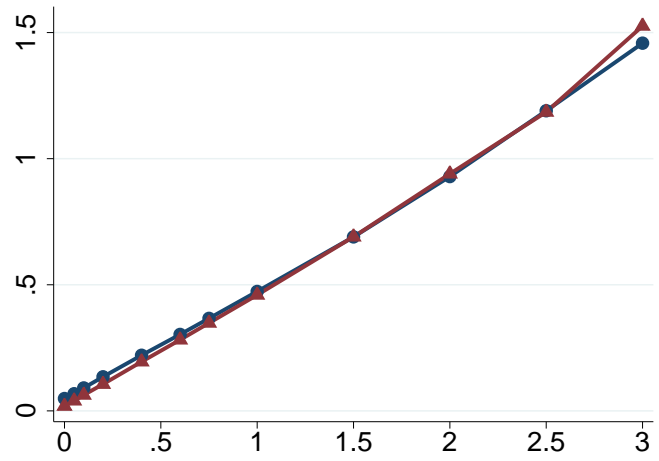

D. Cumulative Employment Drop (4 Years)

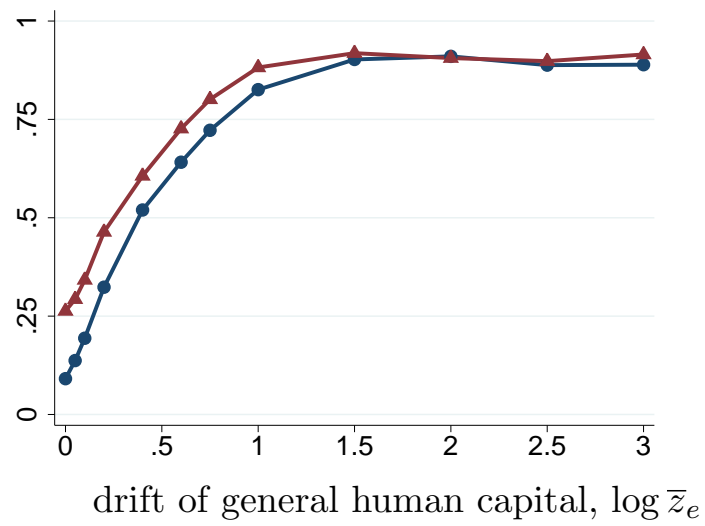

Figure 10: Macaulay Duration of Match Flows

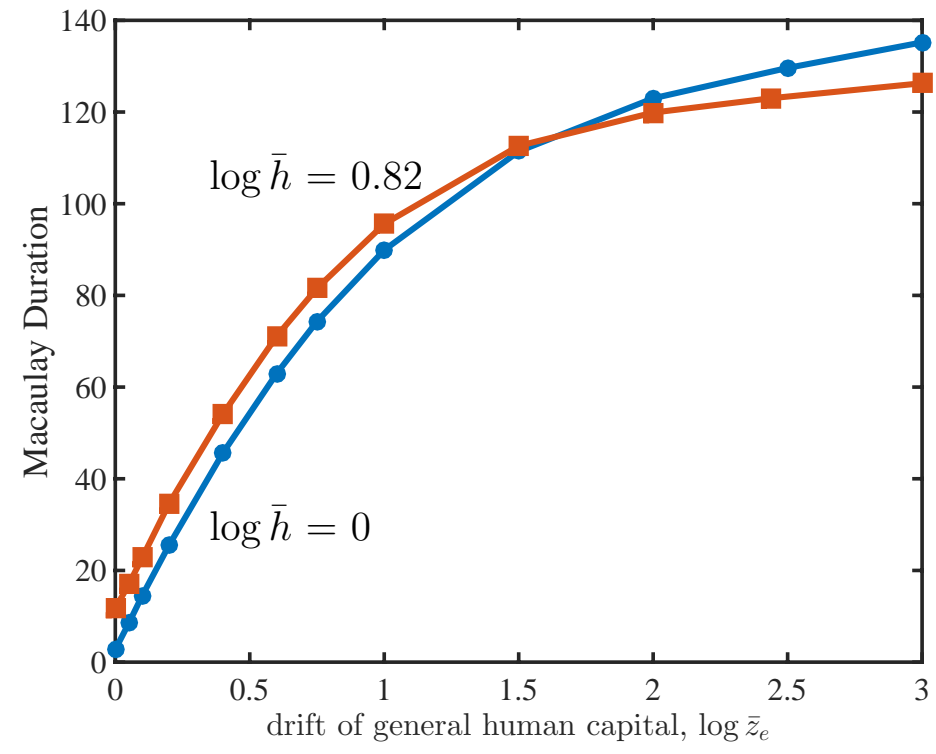




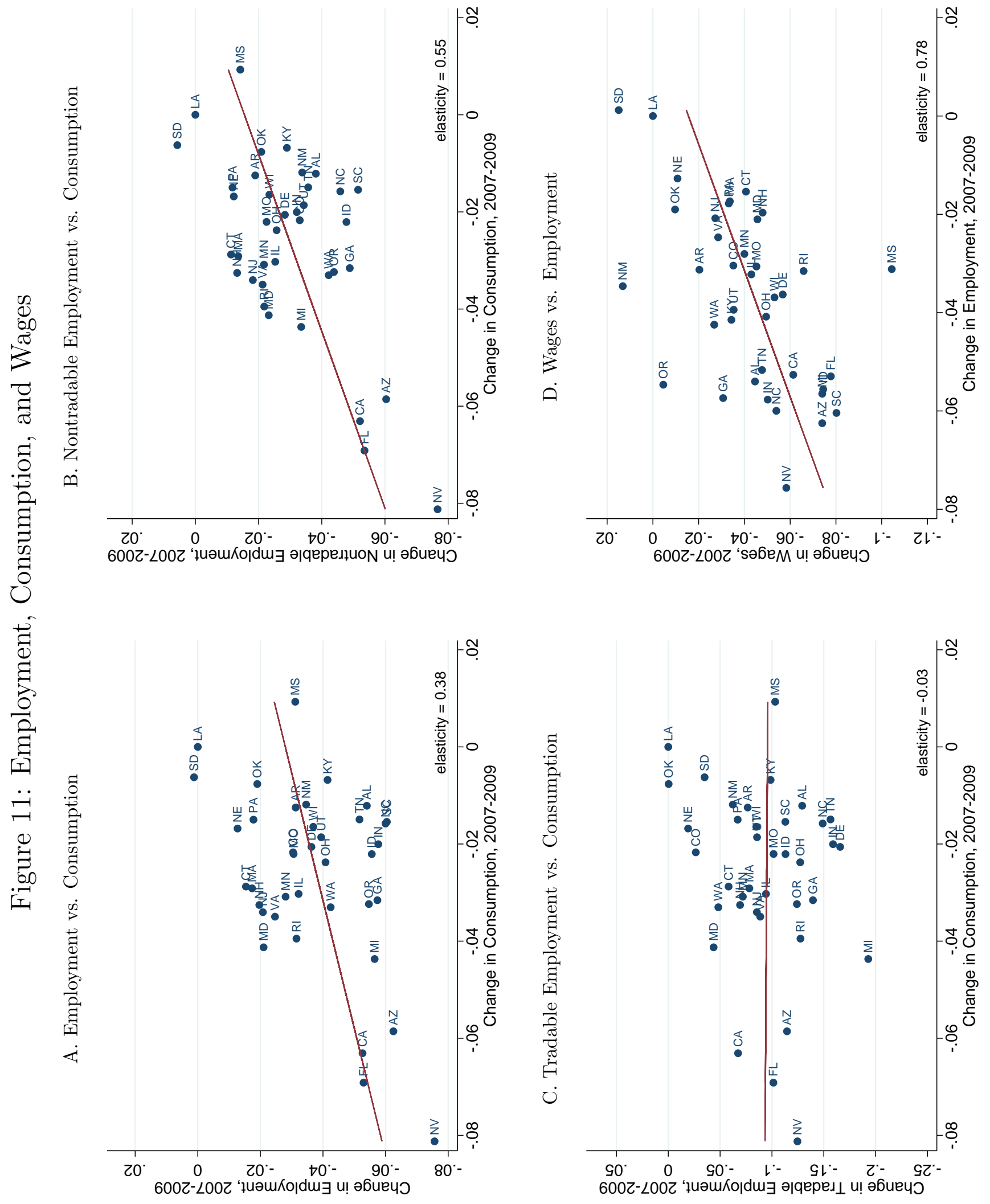


Figure 12: Low Cost of Sectoral Reallocation $(\nu=0.5)$
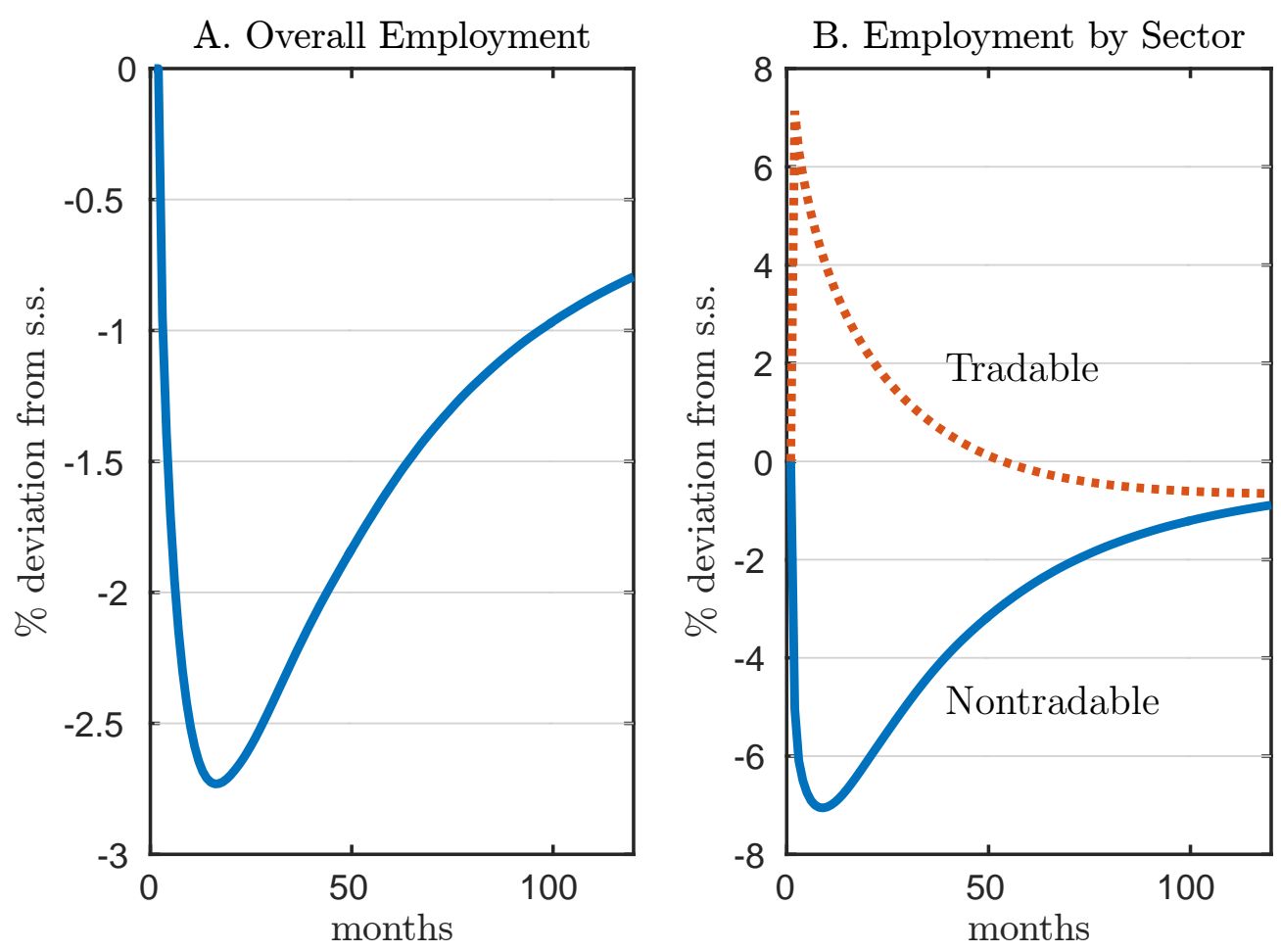

Figure 13: High Cost of Sectoral Reallocation $(\nu=1)$
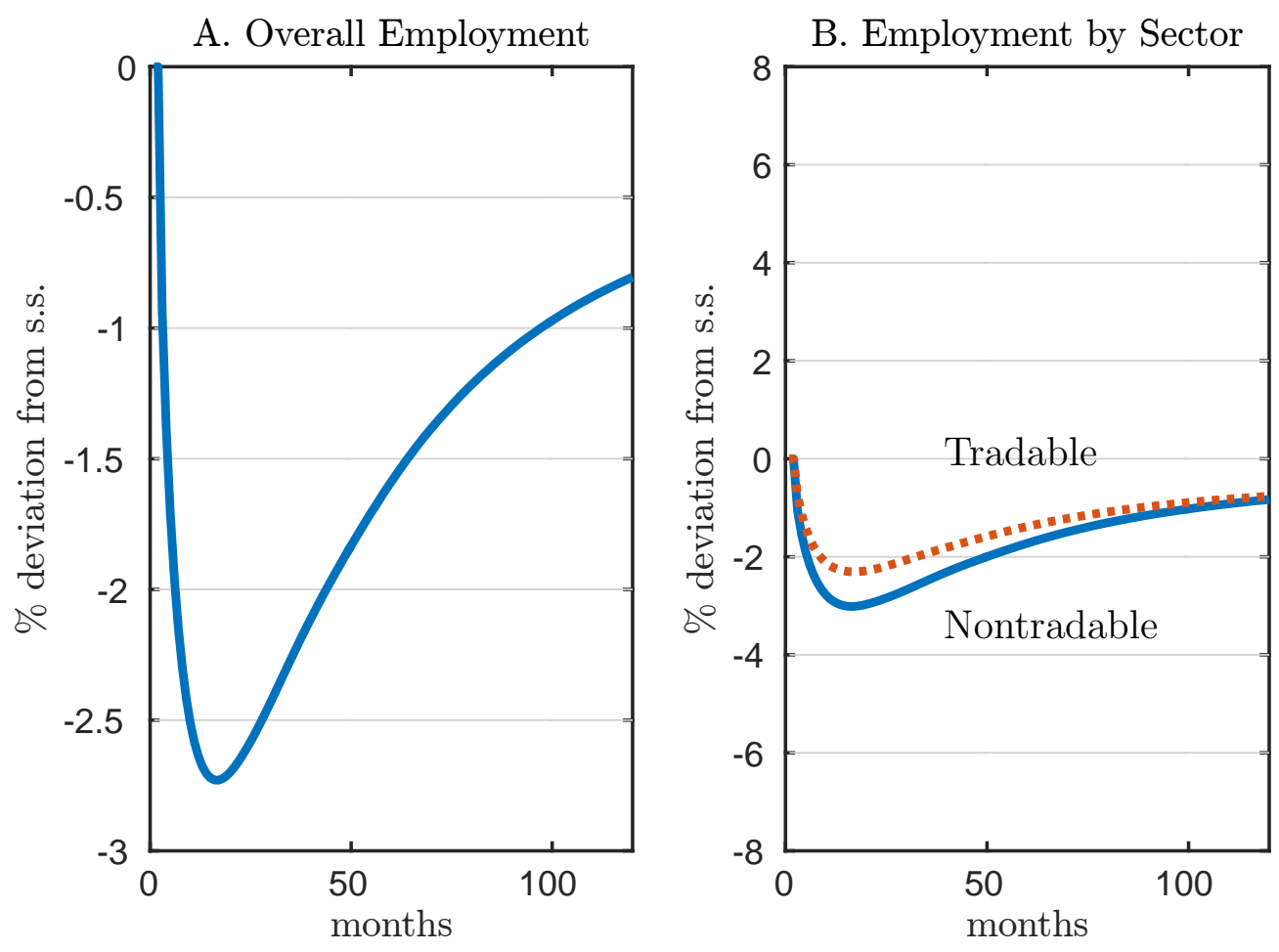